\title{
Modeling challenges and potential solutions for integration of emerging DERs in DMS applications: power flow and short- circuit analysis
}

\author{
Luka V. STREZOSKI ${ }^{1,2}$ (D, Nikola R. VOJNOVIC ${ }^{2}$, Vladimir C. STREZOSKI ${ }^{2}$, \\ Predrag M. VIDOVIC ${ }^{2}$, Marija D. PRICA ${ }^{1}$, Kenneth A. LOPARO $^{1}$
}

\begin{abstract}
We aim to systematically review challenges imposed by emerging distributed energy resources (DERs) to model in two basic distribution management system (DMS) online applications-power flow and short-circuit analysis, as well as to offer a systematic review of potential solutions. In the last decade, electronically coupled DERs became increasingly popular. DERs can employ a wide range of control strategies for power, current, or voltage control, in both normal and faulted conditions. Therefore, DERs cannot be modeled with the traditional PQ (load or generator bus), and PV (generator bus) bus types used for modeling synchronous and induction machines in online power flow calculations. Moreover, because fault currents of DERs are limited to predefined maximal values,
\end{abstract}

CrossCheck date: 29 October 2018

Received: 24 December 2017 / Accepted: 29 October 2018/ Published online: 22 January 2019

(C) The Author(s) 2019

$\triangle$ Luka V. STREZOSKI

1xs533@case.edu

Nikola R. VOJNOVIC

nikovoj@uns.ac.rs

Vladimir C. STREZOSKI

vladimir.strezoski@schneider-electric-dms.com

Predrag M. VIDOVIC

pvidovic@uns.ac.rs

Marija D. PRICA

mxp438@case.edu

Kenneth A. LOPARO

kal4@case.edu

1 Case School of Engineering, Case Western Reserve University, Cleveland, USA

2 Faculty of Technical Sciences, University of Novi Sad, Novi Sad, Serbia electronically coupled DERs cannot be represented with traditional voltage source behind impedance models for online short-circuit calculation (SCC). However, most of the DMS software packages still use the traditional models to represent all DER types, including those that are electronically coupled. This paper shows that there will be high calculation errors in such practice, which makes the system model be an inadequate representation of the system. And this will lead to serious errors in managing, control, and operation of distribution systems. Nonetheless, potential solutions to the challenges are systematically reviewed. Finally, calculation results on a distribution test system with all DER types are used to prove the claim.

Keywords Distributed energy resources (DERs), Distribution management system (DMS), Power flow modeling, Short-circuit modeling

\section{Introduction}

In order to properly monitor, control, optimize, and maintain the secure operation of the systems, distribution system operators use distribution management system (DMS) software packages. DMS consists of supervisory, control and data acquisition (SCADA) system for monitoring, control, and data acquisition and a broad collection of power system applications including planning, optimization, and control. DMS power applications are used in both offline and online operational modes. The offline mode is mainly used for planning and optimization purposes, whereas the online mode is used for the real-time monitoring, control, and maintenance of the secure operation of the distribution system. DMS power applications, in the online mode, need to satisfy two important features 
when large-scale distribution systems are considered: high speed and high accuracy.

Two basic DMS power applications in online mode are power flow and short-circuit calculation (SCC), and almost all other DMS applications are based on either the power flow or SCC results. Power flow is used for calculating the state of the system without contingencies-normal operational state, and most of the other applications that are used for different calculations on the normal operation of the system, such as state estimation, voltage and reactive power optimization, optimal configuration, supply restoration, etc. are based on one or more power flow calculations. On the other hand, SCC is used for calculating the faulted system state. Results obtained by SCC are required for numerous other power applications, such as relay settings and coordination, protection equipment selection, bus-bar design, etc. Therefore, it is essential for DMS to contain efficient and accurate power flow and SCC to have fast calculations and reliable results. Both the speed and the accuracy of the DMS calculations are highly dependent on the system model. Thus, the system model needs to be accurate and not too complex in case of limiting the use in online applications.

For many decades, energy was produced in bulk by large power stations, and then carried through transmission lines to passive distribution systems. Highly efficient models of traditional power systems in both normal [1-5] and faulted conditions [5-10] have been developed. However, in the last two decades, power systems have faced a shift from traditional to current systems in which, besides the bulk production, energy is produced by smaller energy resources connected to distribution systems. At first, distributed energy resources (DERs) were based on the same technology as traditional AC, synchronous and induction, machines for bulk production, but with much smaller size. Therefore, modeling of these systems, at that time, was not a serious challenge, as models for traditional AC machines have been well developed, standardized and widely used in power industry for decades [1-8]. In the normal operational state, these machines can be set to inject constant real and reactive power or to inject constant real power and to keep constant voltage magnitude. Therefore, they have been modeled with single-phase PQ and PV bus types [1-5]. In the faulted system conditions, traditional AC machines completely lose their control, and the response of which depends on their physical characteristics. The fault currents of the machines can be as high as 30 times the rated currents. And they have been modeled as voltage sources behind sub-transient, transient, or steady state impedances [6-8].

However, in the last decade, the connection of DERs to the distribution system through power electronic devices has become increasingly popular [11-14]. In addition to completely electronically coupled DERs (inverter based DERs-IBDERs), DERs can be partially electronically coupled-doubly-fed induction machines (DFIMs). The DFIM technology allows the stator of the machine to be directly connected to the system, while the rotor is decoupled from the system by a back-to-back converter [15-17]. The DFIMs are mainly used in the wind generation industry, where the percentage of wind turbines based on this technology is almost $80 \%$ [16]. The IBDERs are widely used for DERs such as photovoltaics, direct-drive wind turbines, micro-turbines, fuel cells, battery energy storage systems, and flywheels [11-13]. These emerging DERs can employ a wide range of control strategies for power, current, or voltage control, in both normal and faulted operational states [13-15].

In the normal operational state of unbalanced distribution systems, unlike the traditional AC machines, IBDERs and DFIMs can control and block their negative and zero sequence currents [18-26]. Also, they can maintain the symmetrical voltages at their points of common couplings (PCCs) in unbalanced conditions [18-26]. Moreover, these DERs can be bi-directional [15-17]. Therefore, as IBDERs and DFIMs can implement different and more complex control strategies, they cannot be represented with the traditional bus types PQ and PV used for modeling traditional AC machines.

In the faulted state of the system, unlike traditional AC machines, IBDERs and DFIMs in some cases can maintain the control of the fault currents to values not higher than 1.5 times the rated currents [27-33]. These currents are multiple times lower than the fault currents injected by traditional AC machines. Additionally, controllers integrated in DFIMs and IBDERs can implement a wide range of fault current control strategies to specify the real to reactive power ratios. These features greatly benefit the system because of the reduction of stress to system elements caused by large fault currents, and by providing better voltage recovery through reactive power injections during the faulted state. Thus, the response of emerging DERs to faults in the distribution system is completely different from that of traditional AC machines. Additionally, fault ride through (FRT) requirements for DFIMs and IBDERs are introduced into the distribution codes [34-38]. The requirements strictly define how DFIMs and IBDERs should react in the cases of voltage drops at PCCs, caused by faults anywhere in the system. Most of them require that these DERs stay connected to the system throughout the fault state and inject as much reactive power as possible to facilitate faster voltage recovery.

It is clear that the emerging DER technologies impose numerous challenges to modeling and calculations for current distribution systems, in both normal and faulted conditions. Traditional models for modeling all types of 
DERs are mostly applied by DMS software packages, including DFIMs and IBDERs, in both normal and faulted conditions [39, 40]. Models that inaccurately represent the distribution system are used and lead to high errors in calculated results, with a negative effect on the control and secure operation of the system. DMS software packages are a critical part for managing and controlling distribution grids. Inaccurate results caused by using inappropriate models could lead to incorrect decisions made by operators which may eventually lead to serious system faults. Examples of serious negative consequences due to inappropriate models can be found in [41-44]. And the consequences include inaccurate input into the other, more advanced power applications, the false tripping of the protection equipment, prolonged fault clearing times, as well as wrong results of the fault location applications. Therefore, following the most recent literature on modeling and analysis of emerging technologies is crucial for DMS software developers, in order to integrate the appropriate models in their calculations and bridge the gap between new DER technologies and traditional modeling practices. We aim to point out challenges that exist in the integration of DER technologies with distribution system operations, and systematically present a list of potential solutions that could be implemented to avoid consequences caused by using inappropriate models.

There are various high-quality review papers addressing the operational challenges of distribution systems that include the connection of DERs [45-54]. In [46-48], challenges imposed by integration of high penetration of renewable DERs were systematically reviewed. Reference [49] also presents integration challenges and an overview of the market and economic influence of renewable DERs. In [50], an extensive review of distribution automation is presented, and consequently a list of challenges and possible solutions imposed by new technologies is provided. Reference [51] deals with control and automation challenges imposed by renewable generation to the modern power grids, and the focus of the paper are transmission systems. In [52], the need for new distribution system control and planning algorithms of emerging active distribution systems are thoroughly discussed. In [53], the impact of photovoltaic DERs on the voltage regulation is discussed. Finally, in [54], the operational challenges imposed by DERs in both normal and faulted conditions are discussed. In [55-62], the distribution system planning challenges imposed by DERs were discussed. In [55-57], new methods for optimal reactive power planning in modern distribution systems are proposed. These references are focused on integration of intermittent energy resources and their influence on reactive power planning in distribution systems. Reference [58] proposes an optimal placement strategy of energy storage units in distribution systems with high penetration of intermittent distributed generators (DGs). However, the focus of that research is on the market and cost benefits of optimal placement. A similar study is presented in [59], but for optimal placement of energy storages in microgrids. References [60-62] present comprehensive review studies of planning techniques for integration of high penetration of DGs into distribution systems.

However, there are no references in the available literature that systematically review on challenges of modeling and distribution system calculations imposed by integration of emerging DERs. Moreover, systematic review of potential solutions to the existing challenges imposed by emerging DER models does not exist in literature. These challenges were tackled in [63, 64], with no results and potential solutions. Thus we present this paper as modeling and DMS calculations are crucial for the efficient and secure management of distribution systems.

The rest of the paper is organized as follows. In Section 2, the backgrounds of power flow and SCC applications are reviewed. In Section 3, the possible control strategies integrated in different DERs in both normal and faulted conditions are summarized. Consequently, the modeling challenges imposed by the control strategies of emerging DERs are summarized in the latter part of Section 3. In Section 4, potential solutions for the challenges are reviewed. In Section 5, the calculation errors made by using traditional modeling for current distribution systems are shown on a standard test system. Numerical verifications are presented for both normal and faulted states. The paper is concluded in Section 6.

\section{Background of basic power applications and traditional DER modeling}

\subsection{Traditional power flow model and calculation}

The control strategies of traditional AC machines in symmetrical states can be listed as follows: (1) In the case of synchronous machine, the real power is controlled to be: $P_{k}<0, P_{k}=0, P_{k}>0$; they can be generators, compensators, or motors, respectively. In any of these three modes, the reactive power can be controlled to be $Q_{k}<0, Q_{k}=0$, $Q_{k}>0$ by $\mathrm{AC}$ machines, as well as the phase voltage magnitude; (2) In the case of induction machines, the real power is specified to be positive (generator) or negative (motor). The reactive power is always negative and it depends on the magnetizing impedances and phase voltage of the machines.

Control strategies of traditional AC machines are modeled with the traditional bus classification, consisting of 
three types of single-phase buses, as show in Table 1: $\theta \mathrm{V}$ (slack bus), PQ and PV. This classification determines the power flow model and its solution procedure [65].

The angles and magnitudes of phase voltages, as well as the injected real and reactive phase powers are marked with $\theta, U, P$, and $Q$, respectively. Due to the symmetry of the considered systems, any three-phase state variable can be represented with any of its single-phase variables. The second column of Table 1 consists of specified phase variables of different bus types.

The slack bus is the bus with specified voltage angle and magnitude. The generator buses, depending on their control strategies, can be of PQ type, when the real and reactive powers are controlled (specified), or of PV type, when their real powers and voltage magnitudes are controlled (specified).

In power flow calculations, traditional load buses are with specified real and reactive powers-PQ bus types. These powers are specified as constants or functions of voltage magnitudes and frequency [66-75]. In most cases, they are polynomial functions of $2^{\text {nd }}$ degree in voltagesload ZIP models ( $\mathrm{Z}$ stands for constant impedance, I stands for constant current, or load linearly dependent on voltage, and $\mathrm{P}$ stands for constant power) [69-73]. Other types of exponential functions of voltages can be found in [66-68, 71-73, 75]. Linear functions of voltages are presented in [74]. Frequency dependent loads are presented in $[68,73-75]$ with the frequency dependency expressed by multiplying the load function of voltage as a linear function of a frequency deviation.

The third column of Table 1 consists of the unknown phase variables that are listed in the real-valued network state vector $\boldsymbol{X}_{\mathrm{S}}$, which consists of phase voltages (complex representatives $\hat{U}$, or their real-valued pairs of voltage magnitudes $U$ and angles $\theta$ ).

The calculation of the vector was first based on the generic Newton-Raphson iterative method [65]. Fast decoupled power flow, an efficient derivative of the Newton-Raphson method, appeared soon after [76] was applied to the calculation of the power flow model for transmission systems with high $X / R$ ratios of the series branches. Updates of the aforementioned methods for calculation of unbalanced power flow in phase domain are proposed in [77] and in the sequence domain in [78].

Table 1 Traditional single-phase bus classification

\begin{tabular}{lll}
\hline Bus type & Specified operation variable & Unknown state variable \\
\hline$\theta \mathrm{V}$ & $\theta, U$ & \\
$\mathrm{PQ}$ & $P, Q$ & $\theta, U$ \\
$\mathrm{PV}$ & $P, U$ & $\theta$ \\
\hline
\end{tabular}

Backward/forward sweep (BFS) procedures with compensation for loops and generators of PV type appeared around 2 decades ago [79-82] for calculation of radial and weaklymeshed active systems. These procedures are branch-oriented and they are also based on the traditional bus classification $\theta \mathrm{V}, \mathrm{PQ}$, and $\mathrm{PV}$.

However, as stated in the Introduction, the nature of distribution systems has been significantly changed in the last 2 decades. This change is mainly caused by the high penetration of DERs that include DGs, energy storage (ES) systems, or hybrid bidirectional units (DG-ES). In addition to traditional AC machines, DERs include IBDERs (accumulators and flywheels in consumption mode, the same appliances in generation mode, wind and other types of turbines, and photovoltaic panels), DFIMs, etc. Thus, distribution systems transitioned from passive to the active systems, incorporating IBDERs and DFIMs with particularly complex control strategies. These control strategies cannot be accurately represented with the traditional single phase bus classification $\theta \mathrm{V}, \mathrm{PQ}$ and $\mathrm{PV}$. This issue is discussed in Section 3.1.

\subsection{Traditional short-circuit model and calculation}

When the SCC is considered, regardless of the method used for the calculation of the faulted system state, the traditional fault modeling is based on the four decompositions shown in Fig. 1. The fourth decomposition-from the phase domain to the sequence domain is optional [83-85].

As the pre-fault state of the system is known from power flow or state estimation, the SCC is reduced to a calculation of the $\Delta$-circuit state. The main characteristic of the $\Delta$ circuit is that it is passive except at the short-circuit location [5-7] where the injected (fault) currents are non-zero. The AC components of the fault currents are obtained using superposition of the calculated $\Delta$-circuit state and the known pre-fault state. Dynamical sub-transient and transient states exist because of AC machines, and they are approximated as steady-states in the online mode of SCCs

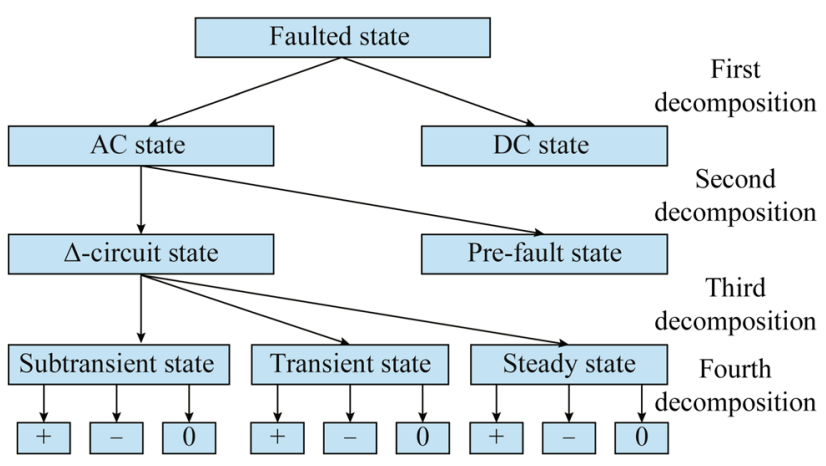

Fig. 1 Four decompositions of faulted system model 
[5-7, 81, 83-87]. Thus, the modeling and calculation of AC states for the sub-transient, transient and steady-state time sequence are performed in the complex domain.

The traditional AC machines completely lose the control during the fault, and their fault response depends on the physical characteristics through sub-transient, transient, and steady-state impedances. The models consist of a voltage source behind impedance, and have been wellestablished in the last decades [3, 6-10].

However, with the emergence of IBDERs and DFIMs, the traditional modeling and calculations for SCCs are not sufficient. As these DERs are decoupled from the system by power electronics, they can maintain the control of the fault currents. Therefore, they cannot be modeled as traditional AC machines. Because of a wide range of possible fault current control strategies integrated in these DERs, there is a need for development of new models, suitable for online SCC of large-scale distribution systems. Moreover, their influence cannot be nulled in the $\Delta$-circuit. Thus, the traditional concept of the passive $\Delta$-circuit cannot be used for SCC for systems with DFIMs and IBDERs [88]. These issues are discussed in Section 3.2.

\section{Control strategies implemented in different DERs}

The layout of the $\operatorname{DER}(k)$ connected to the three-phase bus $k$ is presented in Fig. 2. It can be a traditional AC machine, DFIM, or bidirectional IBDER. Vectors $\hat{\boldsymbol{V}}_{k}, \hat{\boldsymbol{I}}_{k}$, $\boldsymbol{P}_{k}$ and $\boldsymbol{Q}_{k}$ (dimensions $3 \times 1$ ), denote phase voltages, injected currents, and real and reactive powers, respectively.

The sequence domain circuits for $\operatorname{DER}(k)$ can be represented as in Fig. 3 [89].

Depending on the way of the connection to the system, DERs can be divided into four types [88, 90].

1) Type 1: synchronous machine directly connected to the system, e.g. small and medium scale hydro turbines, gas turbines, etc.

2) Type 2: induction machine directly connected to the system, e.g. micro-scale hydro turbines, wind turbines with fixed speed, internal combustion engines, etc.

3) Type 3: DFIM, wind turbines with partially variable speed.

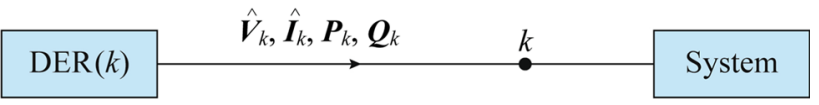

Fig. $2 \operatorname{DER}(k)$ connected to three-phase bus

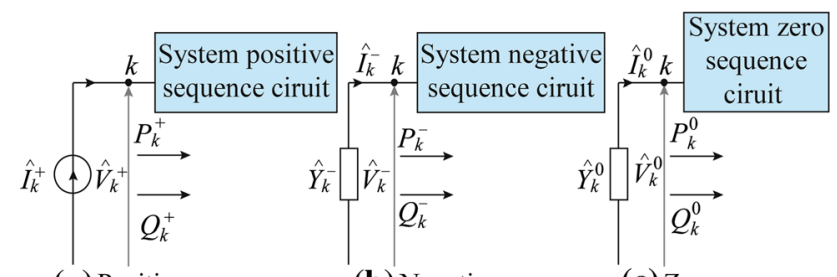

(a) Positive sequence

(b) Negative sequence (c) Zero sequence

Fig. 3 Sequence domain Norton circuits for $\operatorname{DER}(k)$

4) Type 4: IBDER, e.g. photovoltaics, wind turbines with fully variable speed, energy storages, plug-in electric vehicles, fuel cells, etc.

The three different ways of connecting DERs to the system are presented in Fig. 4.

The possible control strategies implemented in different DERs are explained as follows, in Section 3.1 for the normal system state, and in Section 3.2 for the faulted system state.

\subsection{Control strategies of DERs in normal operation state}

Due to the unbalanced nature of distribution systems, caused by single phase laterals, single/two-phase and unbalanced three-phase loads, single and three-phase DERs, and un-transposed structure of three wire and four wire three-phase distribution lines, emerging DERs can employ a wide range of control strategies in the

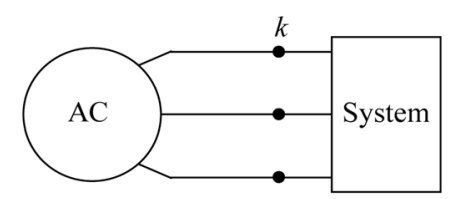

(a) Direct connection

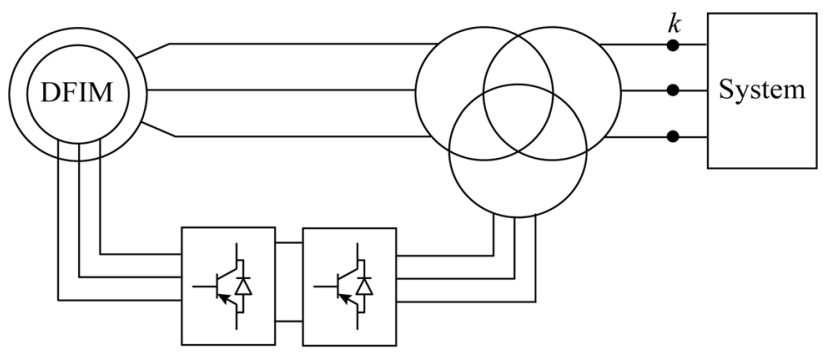

(b) Partly electronically-coupled connection

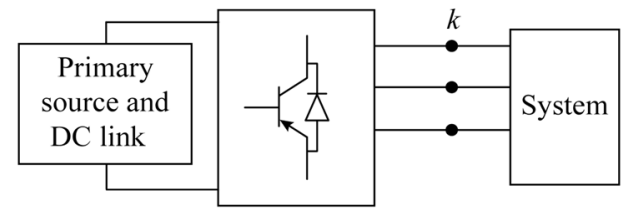

(c) Full scale electronically-coupled connection

Fig. 4 Three ways of connecting $\operatorname{DER}(k)$ 
unsymmetrical operation. Considerable limitation in the traditional modeling of DERs is that by including only single-phase, positive sequence models do not correctly represent the control strategies in unsymmetrical operation.

For traditional AC machines in unbalanced systems and in unsymmetrical states, the variables shown in Table 2 are considered.

Control strategies of synchronous machines in unsymmetrical states are as follows: setting the three-phase real power $P_{k \Sigma}$ and positive sequence voltage magnitude $U_{k}^{+}$, or three-phase reactive power $Q_{k \Sigma}$ in all three modes-generator, compensator or motor, and the subscript $\Sigma$ points to three-phase values. The known values are three-phase real powers $P_{k \Sigma}>0, P_{k \Sigma}=0, P_{k \Sigma}<0$, respectively; the same relations hold for the known three-phase reactive powers $Q_{k \Sigma}$, for each of three operation modes of synchronous machines. In case of induction machines, the three-phase real power $P_{k \Sigma}$ is set; it can be positive (generator) or negative (motor); the three-phase reactive power $Q_{k \Sigma}$ is negative and depends on parameters of the machine (the known magnetizing impedances and voltage of machines). The windings of both types of AC machines are usually delta or ungrounded wye connected; thus, the corresponding admittances $\hat{Y}_{k}^{0}$ from Fig. 3 are equal to zero in most cases.

Even for systems with only traditional AC machines, the traditional single-phase bus classification $\theta \mathrm{V}, \mathrm{PQ}$, and $\mathrm{PV}$ is not sufficient for unbalanced power flow purposes. Namely, the new busses with specified three-phase real and reactive powers need to be introduced. The set of control strategies of traditional AC machines in unsymmetrical states are considered by introducing new three-phase bus types in [89] and include: (1) $(\theta \mathrm{V})_{\Sigma}$ (three-phase slack bus), (2) $\mathrm{P}_{\Sigma} \mathrm{Q}_{\Sigma}$ and (3) $\mathrm{P}_{\Sigma} \mathrm{V}$. The positive sequence voltage magnitude of the $(\theta \mathrm{V})_{\Sigma}$ bus is controlled, and its phase angle is specified. The three-phase real and reactive powers are controlled in the $\mathrm{P}_{\Sigma} \mathrm{Q}_{\Sigma}$ bus type. The three-phase real power and positive sequence voltage magnitude are controlled in the $\mathrm{P}_{\Sigma} \mathrm{V}$ bus type. The models in [89] significantly increased the accuracy of the traditional power flow

Table 2 Phase domain variables associated to the three-phase $\operatorname{DER}(k)$

\begin{tabular}{ll}
\hline Basic variable & Derived variable \\
\hline$P_{k \mathrm{a}}, Q_{k \mathrm{a}}, U_{k \mathrm{a}}, \theta_{k \mathrm{a}}$ & $\hat{I}_{k \mathrm{a}}=\left(P_{k \mathrm{a}}-\mathrm{j} Q_{k \mathrm{a}}\right) /\left(U_{k \mathrm{a}} \mathrm{e}^{-\mathrm{j} \theta_{k \mathrm{a}}}\right)$ \\
$P_{k \mathrm{~b}}, Q_{k \mathrm{~b}}, U_{k \mathrm{~b}}, \theta_{k \mathrm{~b}}$ & $\hat{I}_{k \mathrm{~b}}=\left(P_{k \mathrm{~b}}-\mathrm{j} Q_{k \mathrm{~b}}\right) /\left(U_{k \mathrm{~b}} \mathrm{e}^{-\mathrm{j} \theta_{k \mathrm{~b}}}\right)$ \\
$P_{k \mathrm{c}}, Q_{k \mathrm{c}}, U_{k \mathrm{c}}, \theta_{k \mathrm{c}}$ & $\hat{I}_{k \mathrm{c}}=\left(P_{k \mathrm{c}}-\mathrm{j} Q_{k \mathrm{c}}\right) /\left(U_{k \mathrm{c}} \mathrm{e}^{-\mathrm{j} \theta_{k \mathrm{c}}}\right)$ \\
\hline
\end{tabular}

model and its calculation procedure for modeling the AC machines in unsymmetrical operation.

However, when IBDERs and DFIMs are considered, the bus types need to be further expanded, as with the aforementioned types, their control strategies are only partially covered [18-22, 91-101]. IBDERs and DFIMs are connected to the system via voltage sourced converter (VSC). VSC is voltage or current controlled and can be equipped with voltage regulator and real power controller or $d q$ current controllers [19, 91, 92]. The objective of DER controllers is to achieve either constant three-phase power regulation or voltage regulation. There are two types of VSC configurations [19]: a three- and four-wire configuration. When three-wire configuration VSC is realized, no zero-sequence current is exchanged at the PCC of DER. When in a three or four-wire VSC, there is no active control of negative-sequence current components, then the negative-sequence admittance is present and negative-sequence current is not necessarily nulled, as shown in Fig. 3.

Detailed control strategies for IBDERs and DFIMs are examined in literature, and it is concluded that besides control strategies that can be integrated in the traditional AC machines, IBDERs and DFIMs can employ the following five additional and important control strategies [18-22, 91-102]: (1) control of three-phase real and reactive power providing symmetrical positive sequence voltages; (2) control of three-phase real power and positive sequence voltage magnitude providing symmetrical (positive sequence) voltages; (3) control of three-phase real and reactive power with additional control of negative sequence current; (4) control of three-phase real power and positive sequence voltage magnitude with additional control of negative sequence current; and (5) control of three phase real power and positive sequence current magnitude. These advanced control strategies sense positive sequence voltage and current components at the PCCs of IBDERs and DFIMs, and then provide special VSC switching processes [91]. The control of zero sequence currents is the same as for AC machines [12], [18-22]. Finally, the distributed slack bus is proposed in $[23,103,104]$ for microgrids in autonomous operation.

The above discussion shows that the traditional bus classification $\theta \mathrm{V}, \mathrm{PQ}$, and $\mathrm{PV}$ is far from sufficient for modeling and analysis of unbalanced power flows in distribution systems with IBDERs and DFIMs, and new bus types, as proposed in recent literature, requiring proper representation of these emerging DERs and their advanced control strategies. The recently proposed bus types are systematically listed and explained in Section 4.1. 


\subsection{Control strategies of DERs in faulted system state}

Regarding IBDERs and DFIMs, fault responses are quite different from for traditional AC machines, which will be explained thoroughly in the following.

\subsubsection{Fault currents injected by emerging DERs}

Unlike traditional AC machines, IBDERs and in some cases DFIMs can maintain the control of their fault currents [27-33]. For DFIM, this strongly depends on the method used for the protection of the rotor side converter. DFIM is partially electronically coupled, as its rotor is coupled to the system through the power converter, whereas its stator is directly connected to the system [27-30]. DFIM is usually equipped with the protection device known as a crowbar, which short-circuits the rotor terminals to protect the converter if a severe fault is detected [15], [27-30]. If this happens, the model of DFIM becomes the same as the induction machine model, with the crowbar resistance added to its circuit. This model is used in most of the recent literature regarding the SCC of distribution systems with DFIMs [28-30], as well as in international standards for fault calculations [105-107]. However, if the fault is not that severe, e.g. if it occurs far from the DFIM, the crowbar will not react and the converter will continue to control the injected fault current [15-17, 28-30]. Finally, if a more upto-date protection scheme is used where the converter is active throughout the entire fault period, the converter will continue to control the current even in cases of severe faults. This type of converter protection is known as a chopper [15]. In the last two cases, DFIM will maintain the control of its injected fault current and it cannot be modeled as a traditional AC machine. In these cases, DFIM model will depend upon the control strategy implemented in the power converter. Therefore, using the induction generator models for representing DFIMs in all cases, as suggested in most of the recent literature [28-30] and in international standards for fault calculations [105-107], would introduce high calculation errors, which is discussed in Section 4.2, as well as in the result section.

IBDERs are fully decoupled from the grid by threephase inverters. This technology is used by most of the emerging DERs such as photovoltaics, direct-drive wind turbines, micro-turbines, fuel cells, batteries for energy storage, and flywheels [17]. The electrical model of the IBDER is completely dependent on the control strategy implemented in the inverter. When a fault occurs in the system, IBDER switches to a current-limiting mode with a predefined current limit [15-17]. Controllers are set either to inject only positive sequence currents or (less often) to control both positive and negative sequence currents, while zero sequence currents are always blocked [15-17]. The current limit is predefined and integrated in the inverter, and does not exceed 1.5 times the rated currents. Thus, for IBDERs the traditional models represented by ideal voltage sources behind impedances are completely inadequate and cannot be used in any case. This is also discussed in Section 4.2 as well as in the results section.

The control strategies implemented in IBDERs and DFIMs are provided by the manufacturer or dictated by the FRT requirements of the specific country. As the number of IBDERs and DFIMs constantly increases, more and more countries have started introducing the FRT requirements to their distribution codes [34-38]. Therefore, it is most likely that in the near future, manufacturers will be required to tune the control strategies of DERs in accordance with the specific FRT requirements, and the fault models for DERs should be developed in accordance with the FRT requirements.

\subsubsection{FRT requirements for emerging DERs}

Distribution codes require from electronically coupled DERs to stay connected to the system during the fault, and to support the distribution system by injecting reactive power throughout the duration of a fault [34-38]. The Irish and the German distribution codes require IBDERs and DFIMs to provide reactive current at their PCCs with a contribution of at least $2 \%$ of the rated current per percent of the voltage drop [34-37]. It means that if the voltage drops to $50 \%$, the reactive current should be $100 \%$ of its rated value, and the requirement is presented in Fig. 5. However, these DERs must control their fault current responses within strictly defined current limits to protect vulnerable power electronic devices [13-15]. The current

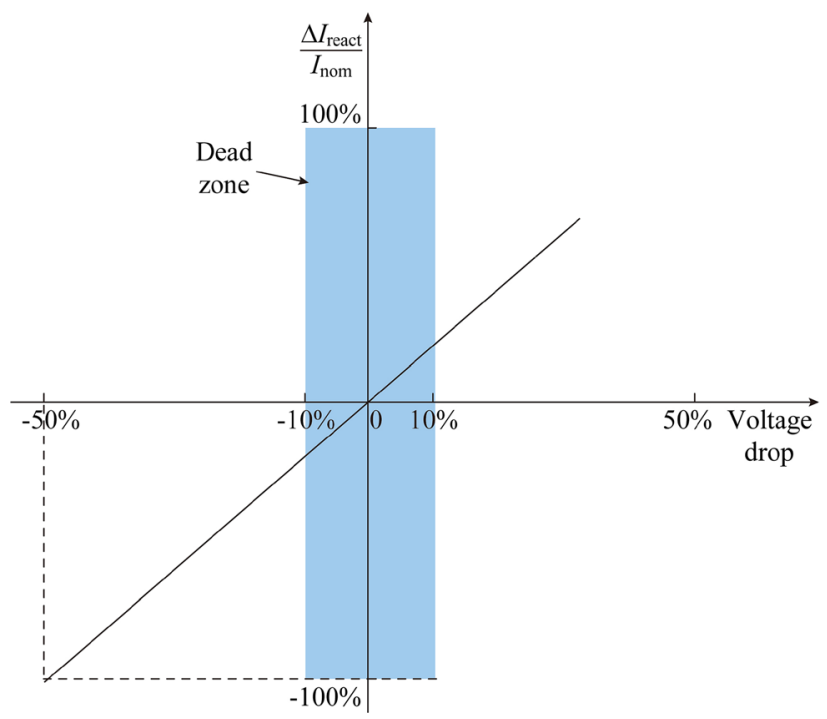

Fig. 5 Requirements for a reactive current injection 
limit differs with different manufacturers, but does not exceed 1.5 times the rated current. Therefore, in cases of severe voltage drops (more than $75 \%$ ), their reactive currents cannot exceed this limit.

Two main FRT requirements regarding electronically coupled DERs are as follows [31, 34-38].

1) To remain connected to the system throughout the duration of the fault.

2) To inject reactive power into the system to support voltage during a system fault.

It is clear that new models for electronically coupled DERs need to be adopted and standardized, in order to have a good approximation of fault responses. In [33, 108-110], the fault models for electronically coupled DERs for dynamical simulations were proposed, and validated on small systems. These models simulate DERs with high precision, but they are too complex. Therefore, calculations with these models would be particularly time consuming, and cannot be used for DMS online calculations implemented on large-scale systems where results are expected in a matter of milliseconds. Moreover, the international standards for fault calculations [105-107] do not provide suitable models for emerging DERs, as they use the traditional induction machine models for representing DFIMs, and provide only brief and inaccurate instructions for modeling IBDERs without considering the FRT requirements. However, in the recent literature, several promising solutions for IBDER and DFIM models have been proposed [88, 90, 111-115], and the proposed models cover several different cases of IBDER and DFIM operation. Therefore, if properly integrated in DMS calculations, these models would be able to represent emerging DERs with high precision in any operating mode, and in that way, avoid inaccurate results. These emerging models will be systematically reviewed and explained in the next section.

\section{Systematic review of potential solutions to modeling challenges imposed by emerging DERs}

\subsection{Normal unsymmetrical operational state}

As stated in Section 3.1, new unbalanced power flow models for distribution systems that contain emerging DERs should be adopted. These methods require a new classification of bus types, so the traditional single-phase bus classification $\theta \mathrm{V}, \mathrm{PQ}$, and $\mathrm{PV}$ needs to be significantly extended. To accurately represent IBDERs and DFIMs, as well as traditional AC machines in unsymmetrical states, nine control strategies of emerging DERs with corresponding new three-phase bus types that accurately represent these strategies are discussed as follows, and presented in Table 3.

1) $(\theta \mathrm{V})_{\Sigma}$ : first variant of the three-phase slack bus. The supply point of the distribution system from the (sub)transmission system that is usually replaced by its Thevenin equivalent with the same form as the models of AC machines. This bus type is introduced in [89]. The positive sequence voltage component of this bus is controlled. Also, this component is the reference variable for angles of all other state variables, so its angle is specified. As it is presented in Table 3, the associated unknown state variables are the complex-

Table 3 New bus type classification

\begin{tabular}{|c|c|c|c|c|}
\hline Bus No. & & Bus type & Specified operation variables & Unknown state variables \\
\hline \multirow[t]{4}{*}{ Traditional bus types } & 1 & $\theta \mathrm{V}$ & $\theta, U$ & \\
\hline & 2 & PQ & $P, Q$ & $\theta, U$ \\
\hline & 3 & PV & $P, U$ & $\theta$ \\
\hline & 4 & $(\theta \mathrm{V})_{\Sigma}$ & $\theta^{+}, U^{+}$ & $\hat{U}^{-}, \hat{U}^{0}$ \\
\hline \multirow[t]{4}{*}{ Three-phase bus types introduced in [89] } & 5 & $\mathrm{P}_{\Sigma} \mathrm{Q}_{\Sigma}$ & $P_{\Sigma}, Q_{\Sigma}$ & $\theta^{+}, U^{+}, \hat{U}^{-}, \hat{U}^{0}$ \\
\hline & 6 & $\mathrm{P}_{\Sigma} \mathrm{V}$ & $P_{\Sigma}, U^{+}$ & $\theta^{+}, \hat{U}^{-}, \hat{U}^{0}$ \\
\hline & 7 & $\mathrm{P}_{\Sigma} \mathrm{Q}_{\Sigma} \mathrm{V}_{\mathrm{sym}}$ & $P_{\Sigma}, Q_{\Sigma}, \hat{U}^{-}=0, \hat{U}^{0}=0$ & $\theta^{+}, U^{+}$ \\
\hline & 8 & $\mathrm{P}_{\Sigma} \mathrm{V}_{\mathrm{sym}}$ & $P_{\Sigma}, U^{+}, \hat{U}^{-}=0, \hat{U}^{0}=0$ & $\theta^{+}$ \\
\hline \multirow[t]{4}{*}{ Three-phase bus types introduced in [102] } & 9 & $\mathrm{P}_{\Sigma} \mathrm{Q}_{\Sigma} \mathrm{I}$ & $P_{\Sigma}, Q_{\Sigma}, \hat{I}^{-}$ & $\theta^{+}, U^{+}, \hat{U}^{-}, \hat{U}^{0}$ \\
\hline & 10 & $\mathrm{P}_{\Sigma} \mathrm{VI}$ & $P_{\Sigma}, U^{+}, \hat{I}^{-}$ & $\theta^{+}, \hat{U}^{-}, \hat{U}^{0}$ \\
\hline & 11 & $3 \theta \mathrm{V}$ & $\theta_{\mathrm{a}}, U_{\mathrm{a}}, \theta_{\mathrm{b}}, U_{\mathrm{b}}, \theta_{\mathrm{c}}, U_{\mathrm{c}}$ & - \\
\hline & 12 & $3 P Q$ & $P_{\mathrm{a}}, Q_{\mathrm{a}}, P_{\mathrm{b}}, Q_{\mathrm{b}}, P_{\mathrm{c}}, Q_{\mathrm{c}}$ & $\theta^{+}, U^{+}, \hat{U}^{-}, \hat{U}^{0}$ \\
\hline Three-phase bus types introduced in $[100,101,116-118]$ & 13 & $\mathrm{P}_{\Sigma} \mathrm{I}$ & $P^{+}, I^{+}$ & $\theta^{+}, U^{+}, \hat{U}^{-}, \hat{U}^{0}$ \\
\hline
\end{tabular}


valued negative- and zero-sequence voltages of this three-phase bus.

2) $\mathrm{P}_{\Sigma} \mathrm{Q}_{\Sigma}$ : traditional three-phase $\mathrm{AC}$ machines as well as IBDERs and DFIMs can be represented with this bus type. In accordance with [89], the control strategy of the DER connected to this bus type consists of specifying the injected three-phase real and reactive powers control. Due to the unsymmetrical system state, the real and reactive powers at the PCC of DER are not equally distributed per phase. Therefore, representing this control strategy with the traditional single-phase PQ bus type, per each phase, would introduce calculation errors. The shortcoming could be omitted by using the $\mathrm{P}_{\Sigma} \mathrm{Q}_{\Sigma}$ bus type. For the threephase real and reactive powers are known variables, while the three sequence components of phase voltages are unknown state variables.

3) $\mathrm{P}_{\Sigma} \mathrm{V}$ : traditional three-phase $\mathrm{AC}$ machines as well as IBDERs and DFIMs can be represented with this bus type. In accordance with [89], the control strategy of the DER connected to this bus type involves setting the injected three-phase real power and the magnitude of the positive sequence voltage component. Due to the unsymmetrical system state, the real power at the PCC of DER is not equally distributed per phases. Therefore, representing this control strategy with the traditional single-phase PV bus type, per each phase, would introduce calculation errors. The shortcoming could be omitted by using by using the recentlyintroduced $\mathrm{P}_{\Sigma} \mathrm{V}$ bus type. For this bus type, the threephase real power and the positive sequence voltage magnitude are known variables, while the angle of the positive sequence voltage component as well as the complex-valued negative and zero sequence voltage components are unknown state variables.

The possibility to control the phase voltages of IBDERs and DFIMs to be symmetrical in unbalanced networks [19] is a particularly important control strategy. And it cannot be represented with any of the previously introduced bus types. By trying to represent these DERs with the traditional bus types, a high calculation error would be introduced, which is numerically presented in the Results Section of this paper. To avoid this error, two new bus types are proposed in [102] and presented in this paper as follows.

1) $\mathrm{P}_{\Sigma} \mathrm{Q}_{\Sigma} \mathrm{V}_{\text {sym }}$ : only IBDERs and DFIMs can be represented with this bus type. It is derived from the $\mathrm{P}_{\Sigma} \mathrm{Q}_{\Sigma}$ type, with additional control of the (positive) symmetry of the voltages, without specifying their magnitude. Both negative and zero sequence voltages are equal to zero. The positive sequence component of phase voltages is an unknown state variable that is described by its angle and magnitude Without introducing $\mathrm{P}_{\Sigma} \mathrm{Q}_{\Sigma} \mathrm{V}_{\text {sym }}$, DFIMs and IBDERs with this control strategy cannot be properly represented. Therefore, it is a significantly new bus type for emerging distribution systems.

2) $P_{\Sigma} V_{\text {sym }}:$ as the previous case, only IBDERs and DFIMs can be represented with this bus type. In accordance with [102], the control strategy is derived from $\mathrm{P}_{\Sigma} \mathrm{V}$ bus type with additional control of the positive sequence symmetry of voltages and the control of voltage magnitudes. Both negative and zero sequence voltage components are equal to zero as in the $\mathrm{P}_{\Sigma} \mathrm{Q}_{\Sigma} \mathrm{V}_{\text {sym }}$ bus type. The angle of the positive sequence voltage component is an unknown state variable.

The possibility to control the negative sequence currents in unbalanced networks [18-20] is the next important control strategy. Like the previous case, it is obvious that none of the existing bus types can accurately represent this control strategy. Moreover, trying to represent it with any of the existing bus types would lead to inaccurate results. This is also clearly illustrated in the Results Section of this paper. To overcome this issue, two new bus types are introduced in [102].

1) $\mathrm{P}_{\Sigma} \mathrm{Q}_{\Sigma} \mathrm{I}$ : only IBDERs and DFIMs can be represented with this type. And it is derived from the $\mathrm{P}_{\Sigma} \mathrm{Q}_{\Sigma}$ type, with additional control of the negative sequence current. The unknown state variables are the same as in $\mathrm{P}_{\Sigma} \mathrm{Q}_{\Sigma}$ bus type. Without the addition of this bus type, IBDERs and DFIMs with negative sequence current control cannot be properly modeled. Thus, it is crucial to add this new bus type to properly represent distribution systems with emerging DERs.

2) $P_{\Sigma}$ VI: as the previous case, only IBDERs and DFIMs can be represented with this bus type. The control strategy is derived from the $\mathrm{P}_{\Sigma} \mathrm{V}$ bus type with additional control of the negative sequence current. The unknown state variables are the same as in $\mathrm{P}_{\Sigma} \mathrm{V}$ bus type.

The possibility to control the real power and current in symmetrical states is one more important control strategy of electronically coupled DERs. For this situation, the single-phase bus type PI is introduced in [100, 116, 117]. This provides an indirect control of reactive power support of the grid. This bus type is generalized as three-phase for grids in unsymmetrical states in [101, 118]. In this case, the positive sequence real power and current are controlled variables. Therefore, it is assumed that the positive 
sequence real power of DER is equal to one third of its three-phase power $\left(\mathrm{P}_{\Sigma}\right)$. This bus type is denoted as $\mathrm{P}_{\Sigma} \mathrm{I}$ as follows.

$\mathrm{P}_{\Sigma} \mathrm{I}$ : only IBDERs and DFIMs can be represented with this bus type. The control strategy of the DER connected to this bus type consists of setting its injected real power and the magnitude of the positive sequence current. Due to the unsymmetrical system state, the real power at the PCC of DER is not equally distributed per phase. For this bus type, the three-phase real power and the positive sequence current magnitude are known variables, while the three sequence components of phase voltages are the unknown state variables.

Reference [102] introduces the second variant of threephase slack bus- $3 \theta \mathrm{V}$, and the three-phase load bus-3PQ. They are shown in Table 3. These buses are derived from traditional single-phase buses- $\theta \mathrm{V}$ (single-phase slack bus) and PQ. The $3 \theta \mathrm{V}$ bus type is used in a case when a weak distribution grid is connected to the strong (sub)transmission grid with specified unsymmetrical voltages (infinite three-phase bus). The 3PQ bus type is a threephase bus, where three (unbalanced) single-phase traditional load buses, as described in Section 2.1, are connected to the distribution grid. The electronically coupled loads, including prosumers and DG-ES, are considered by the other bus types listed in Table 3, depending on the implemented control strategy.

When microgrids are considered, particularly those with autonomous operation, the distributed slack bus (DSB), introduced [23, 104], is based on the droop characteristics $P-f$ and $Q-V[119,120]$ provided in selected DERs. DSB is the fourteenth type of bus classification presented in this paper. It is the third variant of the three-phase slack bus.

With this more complete classification of bus types, the distribution systems with emerging DERs can be accurately represented for unbalanced power flow calculations. Control strategies of emerging DERs are properly modeled and accurately defined by more precise bus types.

Note that without the addition of the recently proposed bus types systematically presented in this paper, unbalanced power flow calculations in presence of emerging DERs would not be possible, as their control strategies cannot be represented with traditional bus types. Namely, by using the results of the traditional power flow calculation, with the traditional single-phase bus classification, for calculating emerging unbalanced networks can introduce high errors. This consequently causes high errors in the results of the other DMS power applications that are based on power flow. The following four DMS power applications are very good examples of the extraordinary sensitivity of their results to errors of power flow calculation: (1) state estimation, (2) voltage/reactive power optimization, (3) optimal configuration, and (4) supply restoration. Power flow calculation is repeatedly used in the execution of all four applications. The results of the first two applications are very sensitive to the bus voltages and the second ones to the branch currents. The bus voltages and the branch currents are main result of power flow calculation, so the precise power flow results are of the highest importance in order to have correct results of other, more advanced DMS power applications.

In the Results Section of this paper, all bus types from Table 3 are integrated into recently proposed power flow calculation procedure for unbalanced distribution systems [102] to verify the accuracy and to show the urgent need for standardization.

\subsection{Faulted system state}

As indicated in Section 3.2, electronically coupled DERs have completely different fault responses from traditional AC machines. The fault currents are limited and often have lower values than the fault currents of traditional AC machines. Moreover, IBDERs inject strictly positive sequence symmetrical currents even in cases of unbalanced faults [27-31]. Only in some rare cases of microgrid implementation, inverters can be set to inject negative sequence currents, to be used as signals that the microgrid switched from grid-tied to islanded operation $[18,19]$. Therefore, the traditional voltage source behind impedance models cannot be used for modeling electronically coupled DERs, and the new models for IBDERs and DFIMs need to be standardized to have a correct approximation of their fault responses.

In [111], new fault models for IBDERs were proposed. The models consist of controlled current sources, with values equal to 2 times their rated currents, in phase with the voltages at PCCs. And they can be used only in cases that reactive current injection requirements are not imposed, and when it is required that the IBDERs inject purely real power in faulted conditions.

However, most of the grid codes require IBDERs to inject reactive power throughout the duration of the fault, in order to improve voltage recovery time. Therefore, in [31, 112], IBDER models consisting of purely reactive controlled current sources with values limited to 1.5 of the rated values were proposed. These models should only be used in cases when the IBDERs inject fault current that is purely reactive.

Even more precise IBDER fault models were proposed in $[88,90]$. These models are based on German FRT requirements and consist of ideal current sources, where the current values are calculated based on the estimated voltages at the PCCs of IBDERs when the fault occurs. In accordance with German FRT requirements for reactive current injection, as shown in Fig. 5, the reactive 
component of the IBDERs fault current is calculated based on this voltage, while the active component is calculated based on the known fault current limit as well as on the pre-calculated reactive component [90]. The current limit is considered to be 1.5 of the rated value, in accordance to [27-31]. In this way, the IBDER fault model is fully correspondent to the actual FRT requirements for both magnitude as well as the ratio of active to reactive components. These models can be easily adapted to fit the FRT requirements of any grid code. Therefore, it is suggested that these models should be used when the FRT requirements are strictly imposed.

Finally, in [111-115], IBDER fault models based on FRT requirements are proposed, but with contributions from both positive and negative sequence currents. In these models, the fault currents are also limited to 1.5 of their rated values. These models should be used in microgrid fault studies, where the negative sequence fault current is required as a signal that microgrid has switched from gridconnected, to islanded operation.

It is clear that IBDERs cannot be represented with the traditional voltage source behind impedance models, in any case. Depending on the different grid code regulation, inverters can be set in different ways, but their fault current magnitudes are always limited and do not exceed 1.5-2 times their rated values. Therefore, they always inject multiple times lower fault currents than the traditional AC machines, and their models need to represent the fact appropriately. Moreover, the ratios of the active to reactive components depend on the grid codes of various countries, so these models need to be flexible to be generally implemented. Finally, in the cases of microgrid implementation, inverters can be set to inject negative sequence fault currents, besides the positive sequence currents, which is also an important control strategy that should be appropriately modeled.

On the other hand, DFIMs present quite a different challenge as their fault responses depend on various factors, and therefore, DFIM fault modeling needs to be extremely flexible. This is an issue with the DFIM modeling proposed in the recent literature [23-30] and the international standards [105-107], as these references propose to model DFIMs like the induction machines. They do not consider the fact that the DFIM behavior in faulted conditions depends on the severity of the fault and on converter protection. Therefore, this practice could lead to inaccurate results in the cases when DFIM manages to control its fault current and could eventually lead to inaccurate setting and coordination of the protection devices in the system.

To avoid the aforementioned issue, an SCC algorithm is proposed in [88], in which a part for deciding which DFIM models should be used based on the location and the severity of the fault and on the converter protection scheme is integrated. The fault severity is estimated based on the voltage drop at the PCC of DFIM, caused by the fault. If this voltage drops below the predefined value, and if the crowbar is used for the converter protection, the DFIM is modeled like an induction machine. However, if the voltage at the PCC of DFIM stays above the predefined value, the DFIM will maintain its current control. In this case, it is modeled as a current source with the value of prefault current of the DFIM. Finally, if chopper protection is used, the DFIM will manage to control its fault current regardless of the fault severity. In this case, it is modeled the same as the IBDER.

Another issue introduced by the connection of electronically coupled DERs is that the traditional way of using the passive $\Delta$-circuit [5-9, 81, 83-85, 87] for modeling and calculation of faulted distribution systems is not valid in the presence of these DERs. Namely, faulted systems have traditionally been solved by decomposition to the passive $\Delta$-circuit state and the known pre-fault state, as shown in Fig. 1. Thus, the entire calculation reduces to the calculation of the passive $\Delta$-circuit. This is not possible with electronically coupled DERs because the fault currents cannot be nulled in the $\Delta$-circuit. Specifically, IBDERs in all cases and DFIMs in case of the chopper protection are modeled with current sources, where their values exceed the pre-fault currents. Therefore, when the decomposition to the pre-fault state and the $\Delta$-circuit state is performed, the values cannot be nulled in the $\Delta$-circuit. This issue is discussed in detail in [88], and consequently the Generalized $\Delta$-circuit concept was proposed that allows the integration of DFIMs and IBDERs into the fault calculations. In the Generalized $\Delta$-circuit, the differences between the

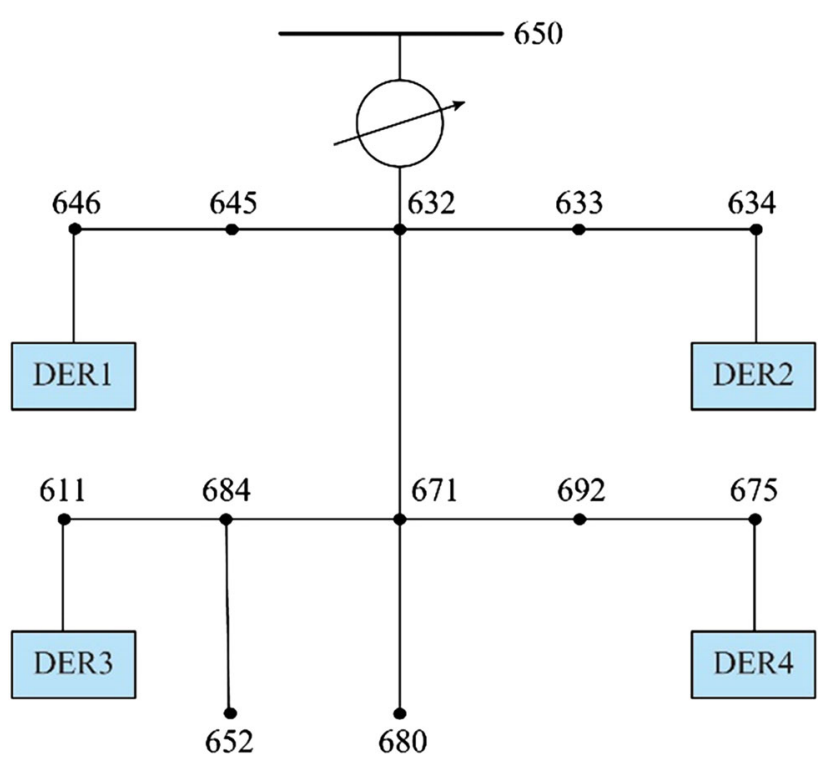

Fig. 6 Modified IEEE 13-node test feeder 
fault currents and the pre-fault currents of these DERs are defined as excess currents. These currents are injected into the busses where controlled DFIMs and IBDERs are connected to the Generalized $\Delta$-circuit and in that way their contribution is fully recognized.

The calculation error that can be introduced by using inappropriate models for electronically coupled DERs is discussed in the next section to point out the urgent need for global standardization of the recently-proposed models.

\section{Numerical tests and discussion}

All numerical tests were carried out on a PC, Intel i32330 M, 4 GB RAM. All calculation procedures were inhouse developed and programmed in FORTRAN 2008.

The modified IEEE 13-node test feeder shown in Fig. 6 was used for numerical verification. The feeder was modified as follows: (1) all two-phase and single-phase sections are replaced with three-phase sections, and the lengths are saved, but the sequence parameters are taken from 4-wire configuration of IEEE 4-node test feeder; (2) the switch 671-692 and transformer 633-634 are replaced with sections that are equal to the modified section 692-675 and 650-632, respectively; (3) the turn ratio of voltage regulator is fixed to one; (4) buses 646, 634, 611, 675 are modified

Table 4 New types of three-phase buses of unbalanced power flow

\begin{tabular}{lllll}
\hline Case & \multicolumn{4}{l}{ Generator bus type } \\
\cline { 2 - 5 } & 646 & 634 & 611 & 675 \\
\hline 1 & $\mathrm{PQ}$ & $\mathrm{PQ}$ & $\mathrm{PQ}$ & $\mathrm{PQ}$ \\
2 & $\mathrm{P}_{\Sigma} \mathrm{Q}_{\Sigma}$ & $\mathrm{P}_{\Sigma} \mathrm{Q}_{\Sigma}$ & $\mathrm{P}_{\Sigma} \mathrm{Q}_{\Sigma}$ & $\mathrm{P}_{\Sigma} \mathrm{Q}_{\Sigma}$ \\
3 & $\mathrm{P}_{\Sigma} \mathrm{V}$ & $\mathrm{P}_{\Sigma} \mathrm{V}$ & $\mathrm{P}_{\Sigma} \mathrm{V}$ & $\mathrm{P}_{\Sigma} \mathrm{V}$ \\
4 & $\mathrm{P}_{\Sigma} \mathrm{Q}_{\Sigma} \mathrm{I}$ & $\mathrm{P}_{\Sigma} \mathrm{Q}_{\Sigma} \mathrm{I}$ & $\mathrm{P}_{\Sigma} \mathrm{Q}_{\Sigma} \mathrm{I}$ & $\mathrm{P}_{\Sigma} \mathrm{Q}_{\Sigma} \mathrm{I}$ \\
5 & $\mathrm{P}_{\Sigma} \mathrm{VI}$ & $\mathrm{P}_{\Sigma} \mathrm{VI}$ & $\mathrm{P}_{\Sigma} \mathrm{VI}$ & $\mathrm{P}_{\Sigma} \mathrm{VI}$ \\
6 & $\mathrm{P}_{\Sigma} \mathrm{I}$ & $\mathrm{P}_{\Sigma} \mathrm{I}$ & $\mathrm{P}_{\Sigma} \mathrm{I}$ & $\mathrm{P}_{\Sigma} \mathrm{I}$ \\
7 & $\mathrm{P}_{\Sigma} \mathrm{Q}_{\Sigma} \mathrm{V}_{\text {sym }}$ & $\mathrm{P}_{\Sigma} \mathrm{Q}_{\Sigma} \mathrm{V}_{\text {sym }}$ & $\mathrm{P}_{\Sigma} \mathrm{Q}_{\Sigma} \mathrm{V}_{\text {sym }}$ & $\mathrm{P}_{\Sigma} \mathrm{Q}_{\Sigma} \mathrm{V}_{\text {sym }}$ \\
8 & $\mathrm{P}_{\Sigma} \mathrm{V}_{\text {sym }}$ & $\mathrm{P}_{\Sigma} \mathrm{V}_{\text {sym }}$ & $\mathrm{P}_{\Sigma} \mathrm{V}_{\text {sym }}$ & $\mathrm{P}_{\Sigma} \mathrm{V}_{\text {sym }}$ \\
9 & $\mathrm{P}_{\Sigma} \mathrm{V}$ & $\mathrm{P}_{\Sigma} \mathrm{Q}_{\Sigma} \mathrm{V}_{\text {sym }}$ & $\mathrm{P}_{\Sigma} \mathrm{Q}_{\Sigma}$ & $\mathrm{P}_{\Sigma} \mathrm{Q}_{\Sigma} \mathrm{I}$ \\
\hline
\end{tabular}

from load to generator buses: a synchronous generator (DER1), induction generator (DER2), DFIM (DER3), and IBDER (DER4) were connected to buses 646, 634, 611, and 675 , respectively; their injected powers are equal to the load powers with opposite directions; these powers are assumed to be the rated power of generators; the rated voltages are equal to $4.16 \mathrm{kV}$; the negative sequence admittances of generators: $Y^{i}=25 \%$ and zero sequence admittance: $Y^{0}=0 \%$.

\subsection{Power flow verification}

In Table 4, all bus types that are used for representing different DERs for this verification are presented. As shown in this table, nine different cases were examined, to clearly verify our claims for the need of introducing new bus types for an accurate representation of the emerging DERs. Each case is explained in detail as follows.

Case 1: the three-phase state is symmetrical in positive sequence. It corresponds to the traditional single-phase power flow. The magnitude of the phase voltage of the slack bus 650 (traditional single-phase $\theta \mathrm{V}$ bus type) is equal to $4.16 \mathrm{kV}$ with an angle equal to zero. The real and reactive powers of all single-phase PQ buses are equal to one third of the sums of given (three-phase, two-phase, single-phase) powers of the corresponding original buses. The control strategies of all DERs are assumed to control real and reactive powers, and they are represented with the traditional PQ bus types in this case. The magnitudes of phase voltages and currents of DERs are presented in Table 5.

Case 2: the three-phase state is unsymmetrical. The symmetry from the Case 1 is disturbed by the loads' real and reactive powers of phases $\mathrm{a}, \mathrm{b}$ and $\mathrm{c}$. The real and reactive powers of phase a loads are increased for $100 \%$, loads of phases b are saved, and the loads of phases c are nulled. DERs are the same as in the previous case, with the same three-phase powers. However, in this case, the power are not equally distributed per phases, because of an unsymmetrical state of the system. Therefore, in this case, DERs need to be represented with $\mathrm{P}_{\Sigma} \mathrm{Q}_{\Sigma}$ bus types introduced in [89]. The results are presented in Table 6. To illustrate the calculation error that would be made if the

Table 5 Magnitude of phase voltage and current of DERs for Case 1

\begin{tabular}{lllllllll}
\hline Phase & \multicolumn{2}{l}{ Voltage magnitude } \\
\cline { 2 - 8 } & $U_{\text {DER1 }}(\mathrm{kV})$ & $U_{\text {DER2 }}(\mathrm{kV})$ & $U_{\text {DER3 }}(\mathrm{kV})$ & $U_{\text {DER4 }}(\mathrm{kV})$ & $I_{\text {DER1 }}(\mathrm{A})$ & $I_{\text {DER2 }}(\mathrm{A})$ & $I_{\text {DER3 }}(\mathrm{A})$ & $I_{\text {DER4 }}(\mathrm{A})$ \\
\hline $\mathrm{a}$ & 4.159 & 4.191 & 4.125 & 4.123 & 36.816 & 68.058 & 26.301 \\
$\mathrm{~b}$ & 4.159 & 4.191 & 4.125 & 4.123 & 36.816 & 68.058 & 26.301 & 133.909 \\
$\mathrm{c}$ & 4.159 & 4.191 & 4.125 & 4.123 & 36.816 & 68.058 & 26.301 \\
\hline
\end{tabular}


Table 6 Magnitude of phase voltage and current of DERs for Cases 2 and 3

\begin{tabular}{|c|c|c|c|c|c|c|c|c|}
\hline \multirow[t]{2}{*}{ Phase } & \multicolumn{4}{|c|}{ Voltage magnitude } & \multicolumn{4}{|c|}{ Current magnitude } \\
\hline & $U_{\mathrm{DER} 1}(\mathrm{kV})$ & $U_{\mathrm{DER} 2}(\mathrm{kV})$ & $U_{\mathrm{DER} 3}(\mathrm{kV})$ & $U_{\text {DER4 }}(\mathrm{kV})$ & $I_{\mathrm{DER} 1}(\mathrm{~A})$ & $I_{\mathrm{DER} 2}(\mathrm{~A})$ & $I_{\mathrm{DER} 3}(\mathrm{~A})$ & $I_{\mathrm{DER} 4}(\mathrm{~A})$ \\
\hline a & 3.552 & 3.660 & 3.337 & 3.355 & 40.614 & 74.887 & 27.216 & 156.202 \\
\hline $\mathrm{b}$ & 4.289 & 4.310 & 4.340 & 4.360 & 33.732 & 63.496 & 27.216 & 119.674 \\
\hline $\mathrm{c}$ & 4.403 & 4.407 & 4.461 & 4.485 & 38.821 & 69.997 & 25.513 & 138.360 \\
\hline
\end{tabular}

Table 7 Results for unbalanced network where all DERs are represented with single-phase bus types

\begin{tabular}{|c|c|c|c|c|c|c|c|c|}
\hline \multirow[t]{2}{*}{ Phase } & \multicolumn{4}{|c|}{ Voltage magnitude } & \multicolumn{4}{|c|}{ Current magnitude } \\
\hline & $U_{\mathrm{DER} 1}(\mathrm{kV})$ & $U_{\text {DER2 }}(\mathrm{kV})$ & $U_{\mathrm{DER} 3}(\mathrm{kV})$ & $U_{\text {DER4 }}(\mathrm{kV})$ & $I_{\mathrm{DER} 1}(\mathrm{~A})$ & $I_{\mathrm{DER} 2}(\mathrm{~A})$ & $I_{\mathrm{DER} 3}(\mathrm{~A})$ & $I_{\mathrm{DER} 4}(\mathrm{~A})$ \\
\hline a & 3.575 & 3.684 & 3.375 & 3.398 & 42.842 & 77.425 & 32.161 & 165.832 \\
\hline $\mathrm{b}$ & 4.285 & 4.305 & 4.331 & 4.350 & 35.742 & 66.261 & 25.062 & 129.537 \\
\hline $\mathrm{c}$ & 4.393 & 4.397 & 4.446 & 4.467 & 34.860 & 64.871 & 24.413 & 126.109 \\
\hline
\end{tabular}

Table 8 Magnitude of phase voltage and current of DERs for Cases 4-6

\begin{tabular}{|c|c|c|c|c|c|c|c|c|}
\hline \multirow[t]{2}{*}{ Phase } & \multicolumn{4}{|c|}{ Voltage magnitude } & \multicolumn{4}{|c|}{ Current magnitude } \\
\hline & $U_{\text {DER } 1}(\mathrm{kV})$ & $U_{\mathrm{DER} 2}(\mathrm{kV})$ & $U_{\mathrm{DER} 3}(\mathrm{kV})$ & $U_{\text {DER4 }}(\mathrm{kV})$ & $I_{\mathrm{DER} 1}(\mathrm{~A})$ & $I_{\mathrm{DER} 2}(\mathrm{~A})$ & $I_{\mathrm{DER} 3 \text { (A) }}(\mathrm{A})$ & $I_{\mathrm{DER} 4}(\mathrm{~A})$ \\
\hline a & 3.526 & 3.631 & 3.294 & 3.308 & 37.579 & 69.244 & 26.901 & 136.95 \\
\hline $\mathrm{b}$ & 4.300 & 4.322 & 4.357 & 4.378 & 37.579 & 69.244 & 26.901 & 136.95 \\
\hline $\mathrm{c}$ & 4.411 & 4.417 & 4.475 & 4.501 & 37.579 & 69.244 & 26.901 & 136.95 \\
\hline
\end{tabular}

Table 9 Magnitude of phase voltage and current of DERs for Cases 7 and 8

\begin{tabular}{|c|c|c|c|c|c|c|c|c|}
\hline \multirow[t]{2}{*}{ Phase } & \multicolumn{4}{|c|}{ Voltage magnitude } & \multicolumn{4}{|c|}{ Current magnitude } \\
\hline & $U_{\text {DER1 }}(\mathrm{kV})$ & $U_{\mathrm{DER} 2}(\mathrm{kV})$ & $U_{\mathrm{DER} 3}(\mathrm{kV})$ & $U_{\text {DER } 4}(\mathrm{kV})$ & $I_{\mathrm{DER} 1}(\mathrm{~A})$ & $I_{\mathrm{DER} 2}(\mathrm{~A})$ & $I_{\mathrm{DER} 3}(\mathrm{~A})$ & $I_{\mathrm{DER} 4}(\mathrm{~A})$ \\
\hline a & 4.097 & 4.134 & 4.066 & 4.086 & 222.885 & 83.237 & 146.714 & 216.816 \\
\hline $\mathrm{b}$ & 4.097 & 4.134 & 4.066 & 4.086 & 73.586 & 64.728 & 8.988 & 124.836 \\
\hline $\mathrm{c}$ & 4.097 & 4.134 & 4.066 & 4.086 & 90.354 & 59.785 & 78.986 & 69.154 \\
\hline
\end{tabular}

traditional PQ bus types were used for modeling DERs in this case, Table 7 is presented, in which all DERs are modeled with the single-phase PQ bus types, per each phase. The results are noticeably different if we compare the results obtained in Tables 6 and 7. Therefore, it can be concluded that in unbalanced networks with unsymmetrical states, even the traditional AC machines cannot be represented with single-phase PQ bus types, as it would lead to inaccurate results.

Case 3: this case is derived from Case 2 with the modification of all DER buses from $\mathrm{P}_{\Sigma} \mathrm{Q}_{\Sigma}$ to $\mathrm{P}_{\Sigma} \mathrm{V}$ type introduced in [89]. The magnitudes of positive sequence voltages of all DERs are taken from the results of Case 2, as shown in Table 6. The results of this case are the same as the results from Case 2, which verifies the validity of models of $\mathrm{P}_{\Sigma} \mathrm{Q}_{\Sigma}$ and $\mathrm{P}_{\Sigma} \mathrm{V}$ bus types.

Case 4: this case is derived from Case 2, but with all DERs switched to IBDERs with the control strategy where the currents can be symmetrical controlled in unsymmetrical network state. Therefore, IBDERs cannot be represented with traditional single-phase bus types, or with the bus types previously introduced in [89]. They need to be represented with the $\mathrm{P}_{\Sigma} \mathrm{Q}_{\Sigma} \mathrm{I}$ bus type, introduced in [102], with $\hat{I}^{-}=\hat{I}^{0}=0\left(\hat{Y}^{-}=\hat{Y}^{0}=0\right)$ from Fig. 3 . The results are presented in Table 8 . The magnitudes of phase voltages are changed compared to the previous case, and the magnitudes of symmetrical phase currents are mutually equal, which verifies the validity of $\mathrm{P}_{\Sigma} \mathrm{Q}_{\Sigma} \mathrm{I}$ bus types. Again, if we 
Table 10 Magnitude of phase voltage and current of DERs for Case 9

\begin{tabular}{|c|c|c|c|c|c|c|c|c|}
\hline \multirow[t]{2}{*}{ Phase } & \multicolumn{4}{|c|}{ Voltage magnitude } & \multicolumn{4}{|c|}{ Current magnitude } \\
\hline & $U_{\mathrm{DER} 1}(\mathrm{kV})$ & $U_{\text {DER2 }}(\mathrm{kV})$ & $U_{\text {DER3 }}(\mathrm{kV})$ & $U_{\text {DER4 }}(\mathrm{kV})$ & $I_{\mathrm{DER} 1}(\mathrm{~A})$ & $I_{\mathrm{DER} 2}(\mathrm{~A})$ & $I_{\mathrm{DER} 3}(\mathrm{~A})$ & $I_{\mathrm{DER} 4}(\mathrm{~A})$ \\
\hline a & 3.784 & 4.129 & 3.579 & 3.593 & 39.207 & 272.8380 & 29.582 & 136.436 \\
\hline $\mathrm{b}$ & 4.201 & 4.129 & 4.241 & 4.263 & 35.090 & 36.0183 & 24.143 & 136.436 \\
\hline c & 4.275 & 4.129 & 4.336 & 4.361 & 38.331 & 86.8530 & 27.074 & 136.436 \\
\hline
\end{tabular}

compare the results from Tables 8 and 5, it can be concluded that in Case 1 also, the traditional single-phase DER modeling is inadequate for representing IBDERs with this control strategy. Moreover, if we compare results from Tables 6 and 8 , it is obvious that the results are different, and therefore these IBDERs cannot be represented with $\mathrm{P}_{\Sigma} \mathrm{Q}_{\Sigma}$ bus type introduced in [89], but they need to be modeled with the $\mathrm{P}_{\Sigma} \mathrm{Q}_{\Sigma} \mathrm{I}$ bus type introduced in [102].

Case 5: this case is derived from Case 4 with the following modifications-instead of the controlled 3-phase reactive powers, the magnitudes of positive-sequence voltages of all generators are maintained equal to the values calculated in Case 4. Therefore, the generator busses need to be represented with the $\mathrm{P}_{\Sigma} \mathrm{VI}$ bus type $\left(\hat{I}^{-}=\hat{I}^{0}=0\right)$ introduced in [89]. The results are the same as in Case 4 as shown in Table 8 , which verifies the validity of the models of $\mathrm{P}_{\Sigma} \mathrm{Q}_{\Sigma} \mathrm{I}$ and $\mathrm{P}_{\Sigma} \mathrm{VI}$ bus types.

Case 6: this case is also derived from Case 4 with the following modifications - instead of the controlled 3-phase reactive powers, the magnitudes of positive-sequence currents of all generators are maintained equal to the values calculated in Case 4. Therefore, the generator busses need to be represented with the $\mathrm{P}_{\Sigma} \mathrm{I}$ bus type $\left(\hat{I}^{-}=\hat{I}^{0}=0\right)$ introduced in [89]. The results are the same as in Cases 4 and 5, as shown in Table 8, which verifies the validity of the models of $\mathrm{P}_{\Sigma} \mathrm{Q}_{\Sigma} \mathrm{I}, \mathrm{P}_{\Sigma} \mathrm{VI}$ and $\mathrm{P}_{\Sigma} \mathrm{I}$ bus types.

Case 7: this case is also derived from Case 2 but with all DERs switched to IBDERs with the control strategy where they control their voltages to be symmetrical in the unsymmetrical network state. Therefore, in Case 7, all DERs need to be represented with the $\mathrm{P}_{\Sigma} \mathrm{Q}_{\Sigma} \mathrm{V}_{\text {sym }}$ bus type introduced in [102]. The results are presented in Table 9. The magnitudes of phase currents are changed by incorporating this bus type, and the phase voltages are symmetrical, which verifies the validity of the $\mathrm{P}_{\Sigma} \mathrm{Q}_{\Sigma} \mathrm{V}_{\text {sym }}$ bus type. By comparing the results from Table 9 with the results from Tables 5, 6, 7 and 8 , the conclusion is like that in the previous case. Namely, IBDERs with this control strategy cannot be represented with neither the traditional single-phase bus types, or with $\mathrm{P}_{\Sigma} \mathrm{Q}_{\Sigma}$ bus type. Rather, they need to be modeled with $\mathrm{P}_{\Sigma} \mathrm{Q}_{\Sigma} \mathrm{V}_{\text {sym }}$ bus type.
Case 8: this case is derived from Case 7 with the following modifications: instead of the controlled 3-phase reactive powers, the magnitudes of symmetrical (positive sequence) voltages of all generators are maintained equal to the values calculated in Case 7 . Therefore, the generator busses need to be represented with the $\mathrm{P}_{\Sigma} \mathrm{V}_{\text {sym }}$ bus type introduced in [102]. The results are the same as in Case 7, as shown in Table 9. This verifies the validity of the models of the $\mathrm{P}_{\Sigma} \mathrm{Q}_{\Sigma} \mathrm{V}_{\text {sym }}$ and $\mathrm{P}_{\Sigma} \mathrm{V}_{\text {sym }}$ bus types.

Case 9: this case is derived from Case 2 as well, but it is assumed that every DER employs different control strategy selected from Table 4: bus 646 (DER1) $-\mathrm{P}_{\Sigma} \mathrm{V}$, bus 634 (DER2) $-\mathrm{P}_{\Sigma} \mathrm{Q}_{\Sigma} \mathrm{V}_{\text {sym }}$, bus 611 (DER3) $-\mathrm{P}_{\Sigma} \mathrm{Q}_{\Sigma}$, and bus 675 (DER4) $-\mathrm{P}_{\Sigma} \mathrm{Q}_{\Sigma} \mathrm{I}$. The results for this case are presented in Table 10 . The phase voltages of $\mathrm{DER}_{2}$ are symmetrical, and the currents of DER4 are also symmetrical. This additionally verifies the validity of $\mathrm{P}_{\Sigma} \mathrm{Q}_{\Sigma} \mathrm{V}_{\text {sym }}$ and $\mathrm{P}_{\Sigma} \mathrm{Q}_{\Sigma} \mathrm{I}$ bus types, introduced in [102]. The results for this case show that different DER control strategies, whether DERs are based on traditional AC machines, as shown in Cases 2 and 3, IBDERs, or DFIMs with additional control strategies to control their voltages or currents to be symmetrical in the unsymmetrical network state, as shown in Cases 4 to 9, can significantly affect the calculation results.

Based on the numerical results, we can find that the traditional single-phase bus classification is far from sufficient for accurate modeling of the emerging systems. From Cases 2-9, the traditional single-phase bus classification cannot be applied for an accurate calculation of unsymmetrical operations of three phase DERs, even for systems with only traditional AC machines. In order to properly take AC machines into account, the traditional bus classification has to be extended by the following threephase bus types: $(\theta \mathrm{V})_{\Sigma}$ (three-phase slack bus), $\mathrm{P}_{\Sigma} \mathrm{Q}_{\Sigma}$ and $\mathrm{P}_{\Sigma} \mathrm{V}$, as shown in Cases 2 and 3 [89]. Moreover, Cases 4-9 show that in order to take emerging DERs into account as well, the aforementioned bus classification has to be further extended, at least by three-phase bus types recently introduced in [102]: $\mathrm{P}_{\Sigma} \mathrm{Q}_{\Sigma} \mathrm{V}_{\text {sym }}, \mathrm{P}_{\Sigma} \mathrm{V}_{\text {sym, }} \mathrm{P}_{\Sigma} \mathrm{Q}_{\Sigma} \mathrm{I}, \mathrm{P}_{\Sigma} \mathrm{VI}, 3 \theta \mathrm{V}$, and $3 \mathrm{PQ}$, as well as by $\mathrm{P}_{\Sigma} \mathrm{I}$ bus type [100, 101, 116-118].

From the comparison of the results presented in Table 5 and results presented in Tables $6,7,8,9$ and 10, it is 
obvious that the grid voltages and branch currents are drastically different. This proves the claim from the end of the Section 4.1 that the results of the traditional power flow calculation of emerging unbalanced networks can be highly erroneous. And this highly influences the errors of results of other DMS power applications based on the power flow results.

For further understanding of implementing new bus types in a power flow calculation of large-scale systems, reference [102] provides a good basis.

\subsection{SCC verification}

For SCC, the transient parameters were used for all DERs. For DFIM, firstly the crowbar protection was assumed. The threshold voltage for the reaction of crowbar was assumed as $70 \%$ of the rated voltage at the PCC of DFIM, in accordance with [88]. For the DFIM modeling, the algorithm from [88] was used for determining which model should be used. For the IBDER, it is assumed that the German FRT requirements are imposed, thus the models from [90] were used. Three-phase short-circuits were simulated at busses 671 and 680 . The results are presented in Tables 11 and 12 for short-circuits at buses 671 and 680, respectively. The fault current values injected by all four DERs are shown in the tables, as well as their percentage values, compared to the rated values.

Finally, Table 13 shows the results for the case same as for Table 11, but with the chopper used for converter protection of DFIM.

From the presented results, it can be concluded that the synchronous and induction machines in the transient time period inject fault currents that range from 4.60 to 6.53 of the rated currents, depending on the location of the fault. Note that for the sub-transient period, these values are several times higher and can be as high as 30 times the rated currents $[1,5,6]$.

Regarding the DFIM, its fault current differs greatly depending on the protection method of converter as well as if it managed to maintain the control or not. For the shortcircuit at bus 671 and the crowbar protection as shown in

Table 11 Calculation results for three-phase short-circuit at bus 671 (crowbar protection for DFIM)

\begin{tabular}{llll}
\hline Fault current & Value (A) & Magnitude (A) & $\begin{array}{l}\text { Percentage of } \\
\text { rated current }(\%)\end{array}$ \\
\hline$I_{\text {DER } 1}$ & $59-\mathrm{j} 188$ & 261 & 653 \\
$I_{\text {DER2 }}$ & $170-\mathrm{j} 198$ & 297 & 593 \\
$I_{\text {DER3 }}$ & $103-\mathrm{j} 171$ & 200 & 500 \\
$I_{\text {DER4 }}$ & $36-\mathrm{j} 48$ & 60 & 150 \\
\hline
\end{tabular}

Table 12 Calculation results for three-phase short-circuit at bus 680 (crowbar protection for DFIM)

\begin{tabular}{llll}
\hline Fault current & Value $(\mathrm{A})$ & Magnitude $(\mathrm{A})$ & $\begin{array}{l}\text { Percentage of rated } \\
\text { current }(\%)\end{array}$ \\
\hline$I_{\text {DER } 1}$ & $53-\mathrm{j} 176$ & 184 & 460 \\
$I_{\text {DER } 2}$ & $-130+\mathrm{j} 157$ & 203 & 508 \\
$I_{\text {DER } 3}$ & $36-\mathrm{j} 17$ & 40 & 100 \\
$I_{\text {DER } 4}$ & $36-\mathrm{j} 48$ & 60 & 150 \\
\hline
\end{tabular}

Table 13 Calculation results for three-phase short-circuit at bus 671 (chopper protection for DFIM)

\begin{tabular}{llll}
\hline Fault current & Value $(\mathrm{A})$ & Magnitude $(\mathrm{A})$ & $\begin{array}{l}\text { Percentage of } \\
\text { rated current }(\%)\end{array}$ \\
\hline$I_{\mathrm{DER} 1}$ & $59-\mathrm{j} 188$ & 261 & 653 \\
$I_{\mathrm{DER} 2}$ & $170-\mathrm{j} 198$ & 197 & 493 \\
$I_{\mathrm{DER} 3}$ & $36-\mathrm{j} 48$ & 60 & 150 \\
$I_{\mathrm{DER} 4}$ & $36-\mathrm{j} 48$ & 60 & 150 \\
\hline
\end{tabular}

Table 11, the voltage at the PCC of DFIM dropped below the threshold value, which was used for determining the fault severity. In this case, the crowbar reacted and the DFIM lost its fault current control. Therefore, the fault response of DFIM was similar to the induction machine, and its fault current is equal to 5 times its rated value. However, for the short-circuit at bus 680 and the crowbar protection shown in Table 12, the voltage at the PCC of DFIM remained above the threshold value. In this case, the crowbar did not react, and the DFIM maintained its prefault current control. Therefore, the fault current magnitude of DFIM was the same as for the rated current. Finally, for the short-circuit at bus 671 and the chopper protection shown in Table 13, the DFIM managed to maintain the predefined fault current control strategy, regardless of the fault severity. In this case, the fault current of DFIM is the same as for the IBDER, and its magnitude is 1.5 of the rated current.

The fault modeling of DFIM is particularly complex, and should be carefully performed. Modeling DFIMs with the induction machine models in all cases, as suggested in [28-30] as well as in international standards [105-107] can cause extremely high errors. As shown in Tables 12 and 13 , when the DFIM manages to maintain the fault current control, its current magnitude is between 1 and 1.5 of its rated value, and therefore multiple times lower than when the induction machine model is used. This error could consequently cause an inaccurate setting and coordination of the protection equipment in the distribution system, which can be a disastrous condition as the fault would not 
be cleared and would then cause significant damage of system equipment. For this purpose, using a decisionmaking algorithm similar to [88] for modeling DFIMs is highly advised, in this way the highly undesirable operating condition explained above would be avoided.

Regarding the IBDER, its fault current is always controlled and dictated by the predefined control strategy (Tables 11, 12, 13). Therefore, its value is always limited and does not exceed 1.5 of the rated current value. Thus, in this case also, using the traditional models would introduce high calculation errors. Therefore, the models with controlled current sources need to be used. Moreover, depending on if the FRT requirements are imposed or not, ratios of active to reactive components of the fault currents of IBDER should be appropriately calculated [88, 90, 111-115], as discussed in Section 4.2.

In [95], a comparison of the SCC method with the models based on the FRT requirements, and the method that uses traditional models, on several large-scale systems is performed and the errors in traditional modeling are clearly shown.

\section{Conclusion}

This paper is intended as a review paper on the state of the art in DER modeling and what is required of DER models in order that they are useful for future power system planning and operations studies. A large number of the latest papers available in the literature have been reviewed, and a systematic list of challenges for the modeling of DERs is provided and based on this, potential solutions are identified.

Unlike synchronous and induction machines, electronically coupled DERs can implement a wide range of control strategies in both normal and faulted conditions. Therefore, their responses completely differ from the responses of traditional AC machines, and they cannot be represented with the same models.

In the normal operational state, the traditional singlephase bus classification needs to be significantly extended in order to accurately represent emerging DERs in unsymmetrical states, which was thoroughly discussed in the paper. And a list of eleven new three-phase bus types introduced in the recent literature was presented. Finally, a complete list of fourteen bus types is presented and explained-thirteen in Table 3 and the DSB. It is shown that by using these bus types, emerging distribution systems can be represented with high precision, and the calculation errors caused by traditional modeling would be avoided.

Regarding the faulted state of the system, unlike synchronous and induction machines, electronically coupled
DERs can control their fault currents. Therefore, these currents are significantly lower than the fault currents of traditional AC machines, and they cannot be represented with the same models. Thus, it is shown in the paper that the calculation error caused by using traditional modeling for current systems could be significant and induce serious issues. Consequently, by using the recently proposed models, based on the FRT requirements, this error would be avoided. Moreover, the traditional way of solving shortcircuit problems, by using the passive $\Delta$-circuit cannot be performed in presence of emerging DERs. Therefore, a new concept of Generalized $\Delta$-circuit is explained. It is shown that by using this concept, emerging DERs can be successfully processed in SCC.

In summary, this paper shows that traditional DER modeling can cause high errors when representing emerging distribution systems, and there is an urgent need for changing this distribution system modeling practices in the near future.

Acknowledgement The authors would like to thank the Ministry of Education and Science of the Republic of Serbia for its support to this research through the Project III-42004.

Open Access This article is distributed under the terms of the Creative Commons Attribution 4.0 International License (http:// creativecommons.org/licenses/by/4.0/), which permits unrestricted use, distribution, and reproduction in any medium, provided you give appropriate credit to the original author(s) and the source, provide a link to the Creative Commons license, and indicate if changes were made.

\section{References}

[1] Grainger J, Stevenson W (1995) Power system analysis, 1st edn. McGraw-Hill, Highstown

[2] Kersting WH (2012) Distribution system modeling and analysis, 3rd edn. CRC Press, Las Cruces

[3] Kersting WH, Phillips WH (1995) Distribution feeder line models. IEEE Trans Ind Appl 31(4):715-720

[4] Kothari DP, Nagrath IJ (2003) Modern power system analysis, 3rd edn. McGraw-Hill, New Delhi

[5] Bergen R, Vittal V (2000) Power system analysis, 2nd edn. Prentice Hall, New Jersey

[6] Anderson PM (1995) Analysis of faulted power systems. IEEE Press, New York

[7] Kersting WH, Phillips WH (1990) Distribution system short circuit analysis. In: Proceedings of the 25th intersociety energy conversion engineering conference, Reno, USA, 12-17 August 1990, pp 310-315

[8] Chen TH, Chen MS, Lee WJ et al (1992) Distribution system short circuit analysis-a rigid approach. IEEE Trans Power Syst 7(1):444-450

[9] Tan A, Liu WHE, Shirmohammadi D et al (1997) Transformer and load modeling in short circuit analysis for distribution systems. IEEE Trans Power Syst 12(3):1315-1321 
[10] Miu KN, Mao Y (2002) Network equivalent models for short circuit analysis. In: Proceedings of 2002 IEEE PES winter meeting, New York, USA, 27-31 January 2002, pp 862-865

[11] Kramer W, Chakraborty S, Kroposki B et al (2008) Advanced power electronic interfaces for distributed energy systems. https://www.nrel.gov/docs/fy08osti/42672.pdf. Accessed Feb 2018

[12] Chakraborty S, Kramer B, Kroposki B et al (2009) A review of power electronics interfaces for distributed energy systems towards achieving low-cost modular design. Renew Sustain Energy Rev 13(9):2323-2335

[13] Teodorescu R, Liserre M, Rodriguez P (2011) Grid converters for photovoltaic and wind power systems. Wiley, West Sussex

[14] Ivanovic ZR, Adzic EM, Vekic MS et al (2012) HIL evaluation of power flow control strategies for energy storage connected to smart grid under unbalanced conditions. IEEE Trans Power Electron 27(11):4699-4710

[15] Howard DF (2013) Short-circuit currents in wind-turbine generator networks. Dissertation, Georgia Institute of Technology

[16] Garcia-Sanz M, Houpis CH (2012) Wind energy systems: control engineering design. CRC Press, Boca Raton

[17] Muljadi E, Gevorgian V (2011) Short-circuit modeling of a wind power plant. In: Proceedings of 2011 IEEE PES general meeting, Detroit, USA, 24-29 July 2011, pp 1-9

[18] Kamh MZ, Iravani R (2011) Active distribution networks: modeling and real-time power management. Lap Lambert Academic Publishing GmbH \& Co, Saarbrücken

[19] Kamh MZ, Iravani R (2010) Unbalanced model and powerflow analysis of micro-grids and active distribution systems. IEEE Trans Power Deliv 25(4):2851-2858

[20] Kamh MZ, Iravani R (2011) Unified three-phase power-flow analysis model for electronically coupled distributed energy resources. IEEE Trans Power Deliv 26(2):899-909

[21] Khushalani S, Solanki JM, Schulz NN et al (2007) Development of three-phase unbalanced power flow using PV and PQ models for distributed generation and study of the impact of DG models. IEEE Trans Power Syst 22(3):1019-1025

[22] Nikkhajoei H, Iravani R (2007) Steady-state model and power flow analysis of electronically-coupled distributed resource units. IEEE Trans Power Deliv 22(1):721-728

[23] Kamh MZ, Iravani R (2012) A sequence frame-based distributed slack bus model for energy management of active distribution networks. IEEE Trans Smart Grid 3(2):828-836

[24] Liu B, Zhang Y (2009) Power flow algorithm and practical contingency analysis for distribution systems with distributed generation. Int Trans Electr Energy Syst 19(6):880-889

[25] Abdel-Akher M, Mahmoud K (2013) Unbalanced distribution power-flow model and analysis of wind turbine generating systems. Int Trans Electr Energy Syst 23(5):689-700

[26] Hwang PI, Jang G, Moon SI et al (2016) Three-phase steadystate models for a distributed generator interfaced via a currentcontrolled voltage-source converter. IEEE Trans Smart Grid 7(3):1694-1702

[27] Williams JR, Karlson B (2012) Wind power plant short-circuit modeling guide. Sandia Nat Lab, Albuquerque

[28] Walling R, Harley R, Miller D et al (2015) Fault current contribution from wind plants. In: Proceedings of 2015 68th annual conference for protective relay engineers, College Station, USA, 30 March-2 April 2015, pp 137-227

[29] Walling RA, Reichard ML (2009) Short circuit behavior of wind turbine generators. In: proceedings of 62nd annual conference for protective relay engineers, Austin, USA, 30 March2 April 2009, pp 492-502

[30] Sulla F, Svensson J, Samuelsson O (2011) Symmetrical and unsymmetrical short-circuit current of squirrel-cage and doubly-fed induction generators. Electr Power Syst Res 81(7):1610-1618

[31] Tu DV, Chaitusaney S, Yokoyama A (2014) Maximum-allowable distributed generation considering fault ride-through requirement and reach reduction of utility relay. IEEE Trans Power Deliv 29(2):534-541

[32] Li J, Zhang XP (2016) Impact of increased wind power generation on subsynchronous resonance of turbine-generator units. J Mod Power Syst Clean Energy 4(2):219-228

[33] Xiao F, Zhang Z, Yin X (2015) Fault current characteristics of the DFIG under asymmetrical fault conditions. Energies 8(10):10971-10992

[34] Tsili M, Papathanassiou S (2009) A review of grid code technical requirements for wind farms. IET Renew Power Gen 3(3):308-332

[35] Bartels W, Ehlers F, Heidenreich K et al (2008) Generating plants connected to the medium-voltage network. http:// grouper.ieee.org/groups/scc21/1547a/email/pdfkz5Zov6vtg.pdf. Accessed 1 June 2008

[36] Tapley B, Hynes D, Hearne T et al (2016) Distribution system operators-ESB networks, Irish distribution code. https://www. esbnetworks.ie/docs/default-source/publications/distribution-codev5-0.pdf?sfvrsn=6. Accessed 5 April 2016

[37] Mokryani G, Siano P, Piccolo A et al (2013) Improving fault ride through capability of variable speed wind turbines in distribution networks. IEEE Syst J 7(4):713-722

[38] Ding G, Gao F, Zhang S et al (2014) Control of hybrid AClDC micro-grid under islanding operational conditions. J Mod Power Syst Clean Energy 2(3):223-232

[39] Hernandez FAI, Canesin CA (2016) Distribution management system and control architecture through a FPGA device for electrical distribution feeders. In: Proceedings of 13th international conference on electrical engineering, computer science and automatic control, Mexico City, Mexico, 26-30 September 2016, pp 1-6

[40] Seal B, Uluski R (2012) Integrating smart distributed energy resources with distribution management systems. https://pdfs. semanticscholar.org/0c56/beabe0d8be31adaa500a4dec5ea3ba76 ed50.pdf. Accessed 1 September 2012

[41] Wang J (2015) Foundational report series: advanced distribution management systems for grid modernization. http://www. ipd.anl.gov/anlpubs/2015/10/121386.pdf. Accessed 4 September 2015

[42] Farhangi H (2010) The path of the smart grid. IEEE Power Energy Mag 8(1):18-28

[43] Veda S, Wu H, Martin M et al (2017) Developing use cases for evaluation of ADMS applications to accelerate technology adoption. https://www.nrel.gov/docs/fy17osti/67614.pdf. Accessed 29 March 2017

[44] Ton D, Wang W, Wang W (2011) Smart grid R\&D by the US department of energy to optimize distribution grid operations. In: Proceedings of IEEE PES general meeting, Detroit, USA, 24-29 July 2011, pp 1-5

[45] Thomas M, Arora S, Chandna VK (2011) Distribution automation leading to a smarter grid. In: Proceedings of IEEE PES innovative smart grid conference, Kollam, India, 1-3 December 2011, pp 1-6

[46] Ackermann T, Andersson G, Soder L (2001) Distributed generation: a definition. Electr Power Syst Res 57(3):195-204

[47] Lopes JAP, Hatziargyriou N, Mutale J et al (2007) Integrating distributed generation into electric power systems: a review of drivers, challenges and opportunities. Electr Power Syst Res 77(9):1189-1203

[48] Akbari MAA, Aghaei J, Barani M et al (2017) New metrics for evaluating technical benefits and risks of DGs increasing penetration. IEEE Trans Smart Grid 8(6):2890-2902 
[49] Amin SM (2011) Smart grid: overview, issues and opportunities: advances and challenges in sensing, modeling, simulation, optimization and control. Eur J Control 17(5-6):547-567

[50] Madani V, Das R, Aminifar F et al (2015) Distribution automation strategies challenges and opportunities in a changing landscape. IEEE Trans Smart Grid 6(4):2157-2165

[51] Wu FF, Moslehi K, Bose A (2005) Power system control centers: past, present, and future. Proc IEEE 93(11):1890-1908

[52] Madureira A, Gouveia C, Moreira C et al (2013) Coordinated management of distributed energy resources in electrical distribution systems. In: Proceedings of 2013 IEEE PES innovative smart grid technologies (ISGT Latin America), Sao Paulo, Brazil, 15-17 April 2013, pp 1-8

[53] Aramizu J, Vieira JCM (2013) Analysis of PV generation impacts on voltage imbalance and on voltage regulation in distribution networks. In: Proceedings of 2013 IEEE PES general meeting, Vancouver, Canada, 21-25 July 2013, pp 1-5

[54] Strezoski L, Sajadi A, Prica M et al (2016) Distribution system operational challenges following integration of renewable generation. In: Proceedings of IEEE energy tech, Cleveland, USA, 5 September 2016, pp 1-6

[55] Dadkhah M, Venkatesh B (2012) Cumulant based stochastic reactive power planning method for distribution systems with wind generators. IEEE Trans Power Syst 27(4):2351-2359

[56] Arefifar SA, Mohamed YARI (2014) Probabilistic optimal reactive power planning in distribution systems with renewable resources in grid-connected and islanded modes. IEEE Trans Ind Electr 61(11):5830-5839

[57] Zou K, Agalgaonkar AP, Muttaqi KM et al (2012) Distribution system planning with incorporating DG reactive capability and system uncertainties. IEEE Trans Sustain Energy 3(1):112-123

[58] Ghofrani M, Arabali A, Etezadi-Amoli M et al (2013) A framework for optimal placement of energy storage units within a power system with high wind penetration. IEEE Trans Sustain Energy 4(2):434-442

[59] Yao L, Yang B, Cui H et al (2016) Challenges and progresses of energy storage technology and its application in power systems. J Mod Power Syst Clean Energy 4(4):519-528

[60] Liu J, Gao H, Ma Z et al (2015) Review and prospect of active distribution system planning. J Mod Power Syst Clean Energy 3(4):457-467

[61] Viral R, Katod DK (2012) Optimal planning of distributed generation systems in distribution systems: a review. Renew Sustain Energy Rev 16(7):5146-5165

[62] Singh D, Singh D, Verma KS (2009) Multiobjective optimization for DG planning with load models. IEEE Trans Power Syst 24(1):427-436

[63] Strezoski L, Strezoski VC, Prica M et al (2017) The need for advanced modeling and calculations of basic EMS and DMS applications for electronically coupled energy resources. In: Proceedings of IEEE power and energy conference in illinois (PECI), Urbana-Champaign, USA, 23-24 February 2017, pp 1-6

[64] Strezoski L, Prica M, Loparo KA et al (2017) Emerging distribution systems: modeling challenges in faulted conditions. In: Proceedings of IEEE Texas power and energy conference (TPEC), College Station, USA, 9-10 Febuary 2017, pp 1-6

[65] Tinney WF, Hart CE (1967) Power flow solution by Newton's method. IEEE Trans Power Appl Syst 86(11):1449-1460

[66] Haque MH (1996) Load flow solution of distribution systems with voltage dependent load models. Electr Power Syst Res 36(3):151-156

[67] Eminoglu U, Hocaoglu H (2005) A new power flow method for radial distribution systems including voltage dependent load models. Electr Power Syst Res 76(1-3):106-114
[68] Hatipoglu K, Fidan I, Radman G (2012) Investigating effect of voltage changes on static ZIP load model in a microgrid environment. In: Proceedings of 2012 North American power symposium (NAPS), 9-11 September 2012, pp 1-5

[69] Bokhari A, Alkan A (1996) Experimental determination of the ZIP coefficients for modern residential, commercial, and industrial loads. IEEE Trans Power Deliv 29(3):1372-1381

[70] Haidar AMA, Muttaqi KM (2014) Behavioral characterization of electric vehicle charging loads in a distribution power grid through modeling of battery chargers. IEEE Trans Ind Appl 52(1):483-492

[71] Pijnenburg P, Saleh S, McGaw P (2015) Performance evaluation of the ZIP model-phaselet frame approach for identifying appliances in residential loads. In: Proceedings of IEEE industry applications society annual meeting, Addison, USA, 18-22 October 2015, pp 1-14

[72] Wang Y, Yhang N, Yang J et al (2017) Linear three-phase power flow for unbalanced active distribution networks with PV nodes. CSEE J Power Energy Syst 3(3):321-324

[73] Abdelaziz M, Farag H, El-Saadany E et al (2017) A novel and generalized three-phase power flow algorithm for islanded microgrids using a newton trust region method. IEEE Trans Power Syst 28(1):190-201

[74] Laghari J, Mokhlis H, Karimi M et al (2014) A new underfrequency load shedding technique based on combination of fixed and random priority of loads for smart grid applications. IEEE Trans Power Syst 30(5):2507-2515

[75] Carne G, Liserre M, Carne G (2016) On-line load sensitivity identification in LV distribution grids. IEEE Trans Power Syst 32(2):1570-1571

[76] Stott B, Alsac O (1974) Fast decoupled load flow. IEEE Trans Power Appl Syst 93(3):859-869

[77] Arrillaga J, Arnold CP (1983) Computer modelling of electrical power systems. Wiley, New Delhi

[78] Zhang XP, Chen H (1994) Asymmetrical three-phase load-flow study based on symmetrical component theory. IEE Proc Gener Transm Distrib 141(3):248-252

[79] Shirmohammadi D, Hong HW, Semlyen A et al (1988) A compensation-based power flow method for weakly meshed distribution and transmission network. IEEE Trans Power Syst 3(2):753-762

[80] Luo GX, Semlyen A (1990) Efficient load flow for large weekly meshed network. IEEE Trans Power Syst 5(4):1309-1316

[81] Rajicic D, Taleski R (1998) Two novel methods for radial and weakly meshed network analysis. Electr Power Syst Res 48(2):79-87

[82] Cheng CS, Shirmohammadi D (1995) A three-phase power flow method for real-time distribution system analysis. IEEE Trans Power Syst 10(2):671-679

[83] Berman A, Xu W (1998) Analysis of faulted power systems by phase coordinates. IEEE Trans Power Deliv 13(2):587-595

[84] Garcia PAN, Pereira JLR, Vinagre MP et al (2004) Fault analysis using continuation power flow and phase coordinates. In: Proceedings of IEEE PES general meeting, Denver, USA, 6-10 June 2004, pp 1-3

[85] Zhang X, Soudi F, Shirmohammadi D et al (1995) A distribution short circuit analysis method using hybrid compensation method. IEEE Trans Power Syst 10(4):2053-2059

[86] Strezoski VC, Bekut DD (1991) A canonical model for the study of faults in power systems. IEEE Trans Power Syst 6(4):1493-1499

[87] Lin WM, Ou TC (2011) Unbalanced distribution network fault analysis with hybrid compensation. IET Gener Transm Distrib 5(1):92-100

[88] Strezoski L, Prica M, Loparo KA (2016) Generalized $\Delta$-circuit concept for integration of distributed generation in real-time 
short-circuit calculations. IEEE Trans Power Syst 32(4):3237-3245

[89] Strezoski VC, Trpezanovski LD (2000) Three-phase asymmetrical load-flow. Int $\mathrm{J}$ Electr Power Energy Syst 22(7):511-520

[90] Strezoski L, Katic VA, Dumnic B et al (2016) Short-circuit modeling of inverter based distributed generators considering the FRT requirements. In: Proceedings of 2016 North American power symposium (NAPS), Denver, USA, 18-20 September 2016, pp 1-6

[91] Seng CK, Tien TL, Nanda J et al (2015) Load flow analysis using improved Newton-Raphson method. Appl Mech Mater 793(3):494-499

[92] Kamh MZ, Iravani R (2012) Steady-state model and powerflow analysis of single-phase electronically coupled distributed resources. IEEE Trans Power Deliv 27(1):131-139

[93] Datta T, Sinha AK, Bajpai P (2016) Three-phase steady state model for unbalanced operation of grid-connected wind generation unit. In: Proceedings of 2016 IEEE annual India conference (INDICON), Bangalore, India, 16-18 December 2016, pp 1-6

[94] Zhao TQ, Chiang HD, Koyanagi K (2016) Convergence analysis of implicit Z-bus power flow method for general distribution networks with distributed generators. IET Gener Transm Distrib 10(2):412-420

[95] Abdelaziz MMA, Farag HE, El-Saadany EF et al (2013) A novel and generalized three-phase power flow algorithm for islanded micro-grids using a Newton trust region method. IEEE Trans Power Syst 28(1):190-201

[96] Mumtaz F, Syed MH, Hosani MA et al (2016) A novel approach to solve power flow for islanded micro-grids using modified Newton Raphson with droop control of DG. IEEE Trans Sustain Energy 7(2):493-503

[97] Eftekharnejad S, Vittal V, Heydt GT et al (2013) Impact of increased penetration of photovoltaic generation on power systems. IEEE Trans Power Syst 28(2):893-901

[98] Tamimi B, Cañizares C, Bhattacharya K (2013) System stability impact of large-scale and distributed solar photovoltaic generation: the case of Ontario, Canada. IEEE Trans Sustain Energy 4(3):680-688

[99] Dzafic I, Neisius HT, Gilles M et al (2012) Three-phase power flow in distribution networks using Fortescue transformation. IEEE Trans Power Syst 28(2):1027-1034

[100] Liu Q, Cai J (2010) A integrated power flow algorithm for radial distribution system with DGs based on voltage regulating. In: Proceedings of 2010 Asia-Pacific power and energy engineering conference, Chengdu, China, 28-31 March 2010, pp 1-4

[101] Yang X, Wei Z, Sun G et al (2013) Power flow calculation for unbalanced three-phase distribution network with DGs based on phase-sequence hybrid modeling. In: Proceedings of 2013 IEEE international conference on smart energy grid engineering (SEGE), Oshawa, Canada, 28-30 August 2013, pp 1-6

[102] Strezoski V, Vojnović N, Vidović P (2018) New bus classification and unbalanced power flow of large-scale networks with electronically interfaced energy resources. Int Trans Electr Energy Syst 28(3):1-16

[103] Gao F, Iravani MR (2008) A control strategy for a distributed generation unit in grid-connected and autonomous modes of operation. IEEE Trans Power Deliv 23(2):850-859

[104] Díaz G, Aleixandre JG, Coto J (2015) Direct backward/forward sweep algorithm for solving load power flows in AC droopregulated microgrids. IEEE Trans Smart Grid 7(5):2208-2217

[105] IEC 60909-0 (2001) Short-circuit currents in three-phase AC systems-Part 0: calculation of short-circuit currents
[106] IEC 60909-0 (2016) Short-circuit currents in three-phase AC systems-Part 0: calculation of short-circuit currents

[107] IEEE Std-551 (2006) IEEE recommended practice for calculating short-circuit currents in industrial and commercial power systems

[108] Erlich I, Kretschmann J, Fortmann J et al (2007) Modeling of wind turbines based on doubly fed induction generators for power system stability studies. IEEE Trans Power Syst 22(3):909-919

[109] Howard D, Habetler T, Harley R (2012) Improved sequence network model of wind turbine generators for short-circuit studies. IEEE Trans Energy Convers 27(4):968-977

[110] Howard DF, Liang J, Harley RG (2014) Short-circuit modeling of DFIGs with uninterrupted control. IEEE J Emerg Sel Top Power Electron 2(1):47-57

[111] Hooshyar H, Baran M (2013) Fault analysis on distribution feeders with high penetration of PV Systems. IEEE Trans Power Syst 28(3):2890-2896

[112] Van Tu D, Chaitusaney S, Yokoyama A (2012) Maximization of distributed generation by considering system operating limits and protection reach reduction as constraints. IEEJ Trans Electr Electron Eng Deliv 7(1):37-45

[113] Wang Q, Zhou N, Ye L (2015) Fault analysis for distribution networks with current-controlled three-phase inverter-interfaced distributed generators. IEEE Trans Power Deliv 30(3):1532-1542

[114] Dag Bulent, Boynueğri AR, Ateş Y et al (2017) Static modelling of micro-grids for load flow and fault analysis. IEEE Trans Power Syst 32(3):1990-2000

[115] Guo WM, Mu LH, Zhang X (2017) Fault models of inverter interfaced distributed generators within a low voltage microgrid. IEEE Trans Power Deliv 32(1):453-461

[116] Li L, Su HS (2017) Power flow calculation of weakly meshed distribution network with distributed generation considering static load characteristics. In: Proceedings of 2017 2nd international conference on energy, power and electrical engineering (EPEE 2017), Shanghai, China, 26-27 November 2017, pp $173-178$

[117] Su Y, Jiang X, Xi Y et al (2015) United power flow algorithm for transmission-distribution joint system with distributed generations. In: Proceedings of 3rd international conference on mechatronics and industrial informatics (ICMII 2015), Zhuhai, China, 30-31 October 2015, pp 919-923

[118] Jiang G, Shu J, Wu Z et al (2012) Unbalanced three-phase power flow calculation based on newton method for micro-grid. Instrum Meas Circuits Syst 127(2):965-972

[119] Souza A, Santos M, Castilla M et al (2015) Voltage security in AC microgrids: a power flow-based approach considering droop-controlled inverters. IET Renew Power Gener 9(8):954-960

[120] Li C, Chaudhary S (2017) Power flow analysis for low-voltage $\mathrm{AC}$ and DC microgrids considering droop control and virtual impedance. IEEE Trans Smart Grid 8(6):2754-2764

Luka V. STREZOSKI received the B.S., M.Sc., and Ph.D. degrees (with honors) in Power Engineering from the University of Novi Sad, Serbia, in 2013, 2014, and 2017 respectively. His Ph.D. research was conducted in a joint supervision between University of Novi Sad and Case Western Reserve University, Cleveland, Ohio. He is currently with the Faculty of Technical Sciences, University of Novi Sad, as an Assistant Professor, as well as with Schneider Electric DMS company, as a Business Analyst at the DMS product management. $\mathrm{He}$ is also involved with Case Western Reserve University, as a visiting affiliate. His research interests include distribution system 
modeling, renewable distribution generation modeling, and integration of DERs into the DMS and DERMS power applications.

Nikola R. VOJNOVIC received his B.S. and M.Sc. degrees in electrical engineering from Faculty of Technical Sciences, University of Novi Sad. Presently, he is an assistant at the same university. He also works as a software engineer at the company Schneider Electric DMS. His research interests include power flow studies of emerging large scale transmission and distribution networks.

Vladimir C. STREZOSKI is professor and Head of the Power Department at the University of Novi Sad, Serbia. Professor Strezoski is also with Schneider Electric DMS Novi Sad, at the position of Director for human development. He received the B.S., M.S., and $\mathrm{Ph} . \mathrm{D}$. degrees in Power Engineering from the University of Belgrade, Serbia, in 1973, 1978, and 1985, respectively. His research interests include power and distribution systems analysis, operation control and planning. In addition, he participates in the development of Schneider Electric's DMS and EMS as industry-grade products.

Predrag M. VIDOVIC received his B.Sc., M.Sc. and Ph.D. degrees in Electrical Engineering from the University of Novi Sad, Serbia, in 2005, 2008 and 2015, respectively. He is with the University of Novi
Sad, Serbia, where he teaches subjects in power systems and distribution networks analysis.

Marija D. PRICA received the B.S. and M.S. degrees in Power Engineering from the University of Novi Sad in 2000 and 2006, respectively, and Ph.D. degree from Carnegie Mellon University, Pittsburgh in 2010. She is an Assistant Professor at Case Western Reserve University, Cleveland, USA. Her research interests include distribution system planning and protection, integration of advanced technologies and control, decision-making for future electricity systems, and optimization of energy storage operation.

Kenneth A. LOPARO is the Nord professor of engineering and Chair of the EECS Department at Case Western Reserve University, Cleveland, USA. His research interests include stability and control of nonlinear systems with applications to large-scale electric power systems, nonlinear filtering with applications to monitoring, fault detection, diagnosis, and reconfigurable control, etc. 